\title{
Model simulation, validation and case study of the 2004 THS of Toyota Prius.
}

\author{
Emmanuel Vinot ${ }^{1}$, Julien Scordia ${ }^{2}$ Rochdi Trigui ${ }^{1}$, Bruno Jeanneret ${ }^{1}$, François Badin ${ }^{3}$. \\ 1: French National Institute on Transport and Safety Research. (INRETS) \\ 2: Imagine society, France. \\ 3: French Petroleum Institute (IFP) \\ Corresponding author: emmanuel.vinot@inrets.fr
}

\begin{abstract}
:
For hybrid vehicles, it is difficult to obtain realistic component models and actual interaction between subsystems without carrying out experiments. INRETS has performed a coupled approach associating simulation using its in house VEHLIB software together with experimental validation. Such an approach makes it possible to obtain validated component models as well as a realistic functioning of the overall vehicle model, which is a necessary step before studying energy optimisation, component resizing and architecture comparison.

This paper highlights the evaluation and modelling of the main components of the Toyota Hybrid Systems (THS) used in the 2004 Prius Vehicle. It focuses especially on the new or improved components compared to the first THS systems. First, the ICE, battery, boost converter, and strategy evaluation and validation process to obtain a useful model of the vehicle and components are examined. Then examples of application are presented concerning energy flow in the vehicle and engine operation compared to a conventional car.
\end{abstract}

Keywords:

Hybrid vehicle, modelling, Toyota Prius, fuel consumption, battery modelling, Hybrid powertrain managements, model validation, Energy flow.

\section{INTRODUCTION}

To reduce fuel consumption and pollutant emission, HEVs (Hybrid Electric Vehicles) represent an interesting alternative to conventional power trains. Whatever the primary energy used, (gasoline, diesel, natural gas, biofuel, hydrogen ...), hybridisation with a reversible storage source (battery, supercapacitor, flywheel,...) allows a substantial energy gain by using energy recovery and optimal energy management between different components.

Since several HEV components and architectures are possible, simulation is identified as a necessary tool to evaluate the performance of new and/or optimized components and advanced controls. The cybernetics approach to the vehicle with its components as subsystems is widely used in different software programs dedicated to this type of simulation (ADVISOR 'Markel 02', PSAT 'Rousseau 00', 'Combes 98'; VEHLIB 'Trigui 04-a' and 'Trigui 04-b').

Two main approaches ('Wipke 99') are often used for hybrid vehicle simulation:

- The forward approach used in PSAT and VEHLIB, based on throttle and brake command generated by a driver's model, often using a PI controller considering required and present speed. This is a causal approach which easily takes into account component limitations and thus allows easy computation of best effort performance. It deals with quantities easily measurable in the vehicle, such as throttle position. Nevertheless, accurate simulation takes a long time to compute into this approach, especially in dynamic phases.

- The backward approach, which supposes that the required speed is exactly met and goes upstream from wheel to engine to calculate how each component performs. It can be used at a low sampling frequency and allows more objective comparison between architectures and components. However, if the driving cycle demand exceeds the capability of the power train, no solution is possible other than iteratively decreasing the target speed, or returning temporally back to a forward stream with a hybrid backward/forward approach as is done in ADVISOR ('Wipke 99').

VEHLIB (Hybrid Electric Vehicle Library) is a cybernetic causal strict forward-looking approach vehicle simulation software program developed in 2000 by the LTE (Environment and Transports Laboratory) at INRETS. VEHLIB uses first level Bond Graph formalism, which means that the subsystems (ICE, electrical machine, battery, gears ...) are modelled according to the bond graph theory principle ('Karnopp 90'): the subsystems use effort and flux input/output variables and respect the energy conservation law. However, the bond graph graphical representation is replaced with a conventional cybernetics representation (figure 2) and the subsubsystems are not necessarily modelled according to the bond graph principle.

VEHLIB allows the simulation of existing vehicles as well as the computation of new architectures or new components using a complete library of components and architectures. It is implemented in the 
MATLAB/Simulink software package. Interfaced with hardware in its HIL (Hardware In the Loop) version ('Trigui 04-b'), it makes it possible to test new architectures or strategies laws with real components (mainly the ICE electrical machine or storage device.). Moreover, coupled with our home optimization backward approach software ('Scordia 05'), it allows the sizing of components and objective comparison between different power trains ('Vinot 07').
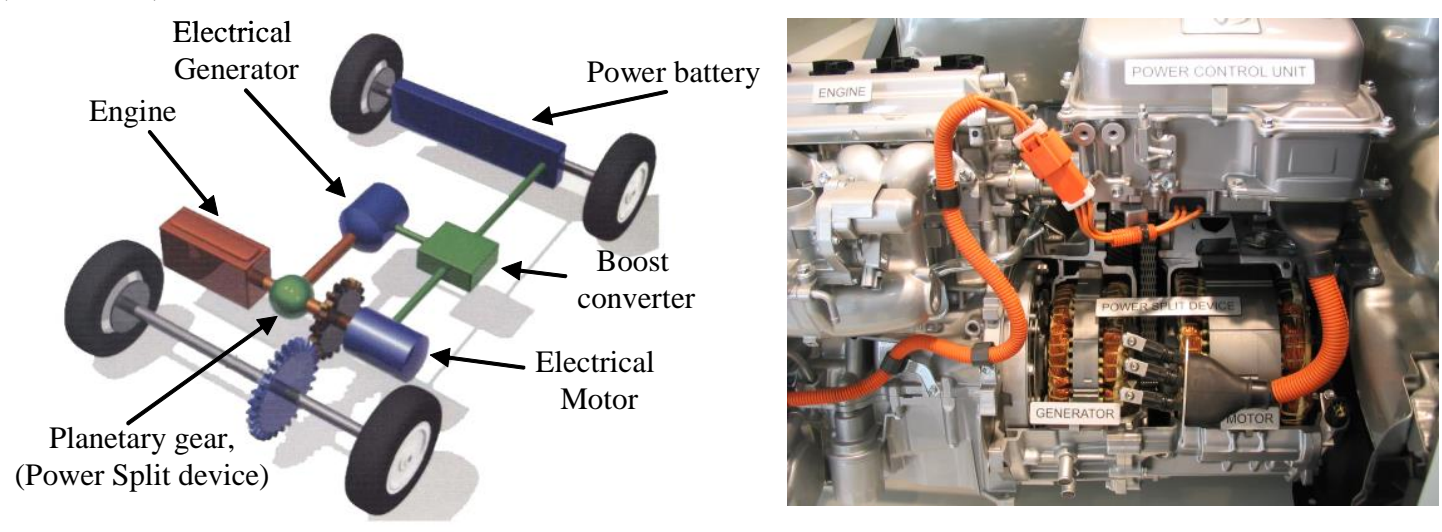

Figure 1 : THS architecture

One of the main difficulties in the development of a vehicle and components library is to obtain relevant and realistic component models and parameters and to evaluate the actual interaction between the subsystems. This is almost impossible without carrying out experiments.

Consequently, our work described in this paper is based on a coupled approach combining simulation on VEHLIB with experimental validation performed on a chassis dyno and battery specific test bench. This allows us to obtain validated component models as well as realistic operation of the overall vehicle model, which is a necessary step before studying energy optimisation, component resizing and architecture comparison.

This paper highlights the evaluation and modelling of the main components of the Toyota Hybrid Systems (THS) used in the 2004 Prius Vehicle. It focuses especially on the new or improved components compared to the first THS systems. First, the ICE, battery, boost converter, and strategy evaluation and validation process to obtain a useful model of the vehicle and components are discussed. Then examples of application are presented concerning energy flow in the vehicle and the engine operation in comparison with a conventional car.

\section{Modelling, Characterisation ANd COMPONENT VAlidation}

\subsection{THS and Toyota Prius Component Models}

The THS ('Yaegashi 98', 'Toyota 03') is well known as it is used in the different Toyota Prius models and in the SUV 05 ('Takaoka 04', 'Kimura 99'). It is mainly composed of an IC engine (ICE), an electrical motor (EM) directly linked to the transmission, and a second electrical machine called a generator (GEN) linked to the ICE via a planetary gear, in turn connected to the transmission (figure 1). Moreover, the two electrical machines are connected to a power battery (BAT), and possibly by a boost converter (CONV). This full hybrid system allows start/stop, electrical mode, regenerative braking and ICE operation in a Torque/Speed curve corresponding to the optimal system efficiency.

The THS system and its components were significantly improved in the second version (THS-II 'Muta 04', table 1) not only by increasing the electrical machines' power but also thanks to:

- $\quad$ addition of a boost converter between battery and machine inverters,

- use of a new NiMh battery and reduction of numbers of elements,

- use of an improved ICE,

- $\quad$ and, due to all of these changes, modification of the strategy management.

Different simulation models of the first THS systems and components have been previously developed ('Rousseau 01', 'Liu 05', 'Wang 02', 'Jeanneret 99') and certain models of THS-II systems ('Rousseau 04') have been presented and validated, yet they did not focus on the improvements and new characteristics of the systems and the components.

Considering all of this modification, it is necessary to modify and improve the model of the 1999 Prius existing in VEHLIB ('Jeanneret 99'), as it is important to have the characteristics of recently developed 
components in order to evaluate the performance of new and/or optimized components and advanced controls.

\begin{tabular}{|c|c|c|c|}
\hline & & Prius 2001 & Prius 2004 \\
\hline Vehicle weight & & $1297 \mathrm{~kg}$ & $1360 \mathrm{~kg}$ \\
\hline \multirow{2}{*}{ Engine } & displacement & $1497 \mathrm{cc}$ & $1497 \mathrm{cc}$ \\
\cline { 2 - 4 } & max power & $52 \mathrm{~kW} @ 4500 \mathrm{rpm}$ & $57 \mathrm{~kW} @ 5000 \mathrm{rpm}$ \\
\hline Planetary gear & ratio(ring,planet,sun) & $2.6(78 / 23 / 30)$ & $2.6(78 / 23 / 30)$ \\
\hline Gear & ratio & 3.905 & 4.113 \\
\hline \multirow{4}{*}{ Electrical Motor } & max power & $30 \mathrm{~kW}$ & $50 \mathrm{~kW}$ \\
\cline { 2 - 4 } & maximum speed & $6000 \mathrm{rpm}$ & $6000 \mathrm{rpm}$ \\
\cline { 2 - 4 } & maximum voltage in use & $275 \mathrm{~V}$ & $500 \mathrm{~V}$ \\
\cline { 2 - 4 } & maximum torque & $300 \mathrm{Nm}(0$ à $940 \mathrm{rpm})$ & $400 \mathrm{Nm}(0 \mathrm{à} 1200 \mathrm{rpm})$ \\
\hline \multirow{4}{*}{ Electrical Generator } & max power & $15 \mathrm{~kW}$ & $30 \mathrm{~kW}$ \\
\cline { 2 - 4 } & maximum speed & $8000 \mathrm{rpm}$ & $10000 \mathrm{rpm}$ \\
\cline { 2 - 4 } & maximum voltage in use & $275 \mathrm{~V}$ & $500 \mathrm{~V}$ \\
\cline { 2 - 4 } & maximum torque & $145 \mathrm{Nm}(0$ à $940 \mathrm{tr} / \mathrm{min})$ & $160 \mathrm{Nm}(0 \mathrm{à} 1800 \mathrm{tr} / \mathrm{min})$ \\
\hline Boost converter & maximum Voltage & none & $510 \mathrm{~V}$ \\
\hline \multirow{3}{*}{ NiMh battery } & NiMh module number & 38 & 28 \\
\cline { 2 - 4 } & nominal energy & $1.8 \mathrm{kWh}$ & $1.3 \mathrm{kWh}$ \\
\cline { 2 - 4 } & nominal voltage & $273.6 \mathrm{~V}$ & $201.6 \mathrm{~V}$ \\
\hline \multirow{2}{*}{ maximum vehicle speed } & electric mode & $50 \mathrm{~km} / \mathrm{h}$ & $60 \mathrm{~km} / \mathrm{h}$ \\
\cline { 2 - 4 } & hybrid mode & $140 \mathrm{~km} / \mathrm{h}$ & $160 \mathrm{~km} / \mathrm{h}$ \\
\hline
\end{tabular}

Table 1 : Toyota Prius components

This study gives us the ICE consumption map model and operating limitations (section 2.2), which is crucial for the study of dynamic performances and the design and sizing of such architecture.

Specific battery evaluations on dedicated test benches were performed and allowed the development of an advanced model (section 2.3) based on non integer derivatives and presently taking into account the diffusion phenomenon in comparison with the ohmic model previously used. This allows better modelling of electrical energy flow and battery losses.

The boost converter between the battery and the two electrical machines and especially the evaluation and modelling of its control (required output voltage, section 2.4) also appeared important for a better evaluation of the inverter and motor losses that depend on the voltage.

Finally, the Strategy and THS-II management were modified to fit the measurement, including high battery charge or discharge modes. This representative rule-based management may thus be compared to optimal strategies ('Vinot 07').

Figure 2 presents the Matlab simulink model of the 2004 Prius version. The two electrical machines are modelled by means of efficiency maps ('Lukic 03'). Mechanical equations allow us to simulate the transmission and the vehicle. The planetary gear (figure 4) is considered as a perfect device respecting the Willis and torque relationships with no internal inertia. Nevertheless, the linked inertia (ICE, GEN, MOT and final drive) are taken into account and an efficiency factor is applied - only to the ring gear - in our model. It is noted that in electrical mode - with the ICE stopped - it behaves like a simple gear device with a ratio corresponding to the planetary gear ratio ( $\left.\mathrm{k}=-\mathrm{N}_{\text {teeth_ring }} / \mathrm{N}_{\text {teeth_sun }}\right)$.
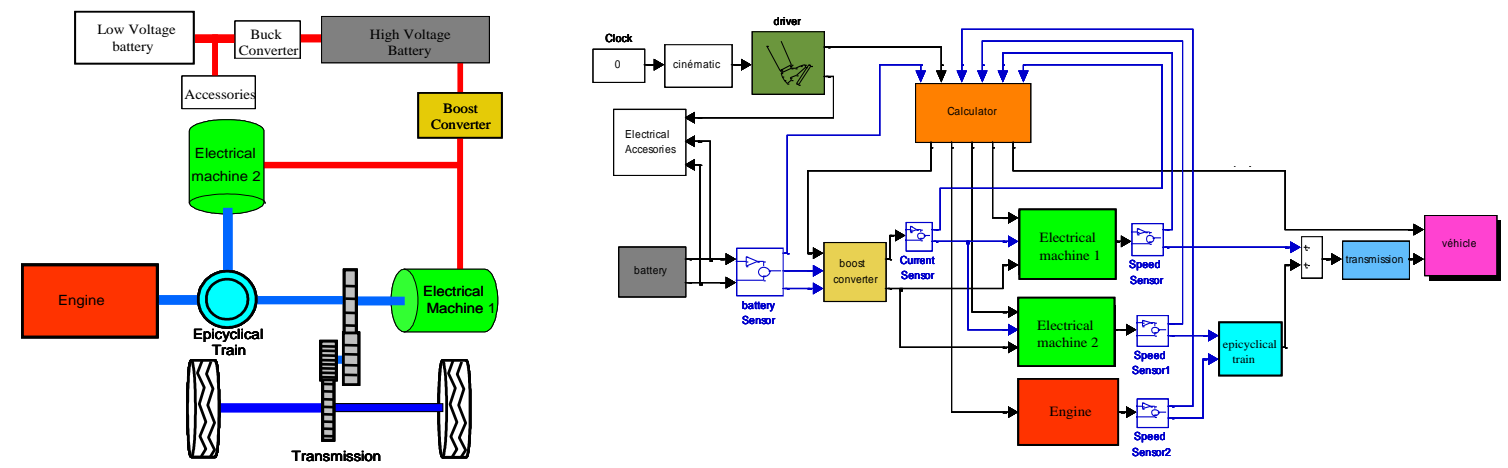

Figure 2: VEHLIB Model 


\subsection{In situ ICE evaluation}

\subsubsection{Fuel consumption map of the ICE}

\subsubsection{In situ ICE evaluation}

As it is very difficult to run an ICE on a test bench independently from its original vehicle and its related calculators, the ICE characteristics (in particular the consumption map) were recorded with in situ measurement, with the ICE inside the vehicle. To obtain the consumption or CO2 emission maps, it is important to cover the largest possible area in the Torque/Speed domain. This is particularly difficult with the THS-II as its goal is precisely to run the ICE in a Torque/Speed curve corresponding to the optimal system efficiency ('Yaegashi 98', 'Takaoka 04') independently of the wheel speed.

Fortunately, there are mechanical limitations in the THS-II (see section 2.2.2). Thus to balance the planetary gear at high vehicle speed, the ICE has to run at a minimum speed even if the required torque is well below the optimal curve (figure 4).

A chassis dynamometer is used in the speed regulation mode. In this mode, the chassis dynamometer adapts its torque to the power generated by the car, which is set by the driver via the throttle position. Thus, for different throttle positions, different ICE steady operating points (figure 3) may be reached. One could note that at high vehicle speed, the operating points are not in the best Break specific consumption (Bsc) range: they follow a constant rpm vertical line (for 135 to $157 \mathrm{~km} / \mathrm{h}$ ) imposed by the power train's mechanical limitations (section 2.2.2), whereas at equal power, smaller rpm and a greater torque would have allowed a better Bsc.

One could note that the ICE torque measurement becomes very complicated if the ICE is being operated in the power train. Some different methods can be used such as direct measurements via a torque sensor located in the power train, a calculation connected to an air flow measurement, or a direct measurement of cylinder pressure. The last method was implemented in the 2004 Prius using a system developed at the IFP (French Petroleum Institute).

Consumption is measured using a carbon balance method with a Constant Volume Sampling exhaust gas measurement. Thus, due to the delay between emission and measurement and gas dilution, only steady point measurement can be accurately performed to generate the specific consumption (Bsc) maps model. Thus, for vehicle simulation we assume that the dynamic consumption is a succession of steady state consumptions using a typical dynamic response of the ICE torque. This assumption was evaluated when performing dynamic cycles using VEHLIB in its HIL version ('Trigui 04-b'). It clearly appears that this assumption does not influence the results (global consumption) significantly ('Trigui 07', 'Jeanneret 04').

\subsubsection{Resulting Maps}

Figure 3 shows the specific consumption (Bsc) obtained with this method. One could note that the best Bsc is very good $(225 \mathrm{~g} / \mathrm{kWh})$ compared to a conventional gasoline ICE of that size, mainly due to the HighExpansion Ratio Cycle (Atkinson cycle 'Toyota 03'), and close to those given by Toyota data ('Takaoka 04').

The red curve, representing the central part of the operating point range observed during our measurement campaign for different vehicle uses, allows the ICE to work in a good Bsc range. This curve has been considered as a goal for the THS_II systems to operate the ICE in our strategy model (section 2.5).

As previously explained, to obtain the largest possible range, constraining tests have to be performed (high speed and high ICE torque/power). These tests are also especially useful to understand ICE and vehicle limitations (2.2.2). 


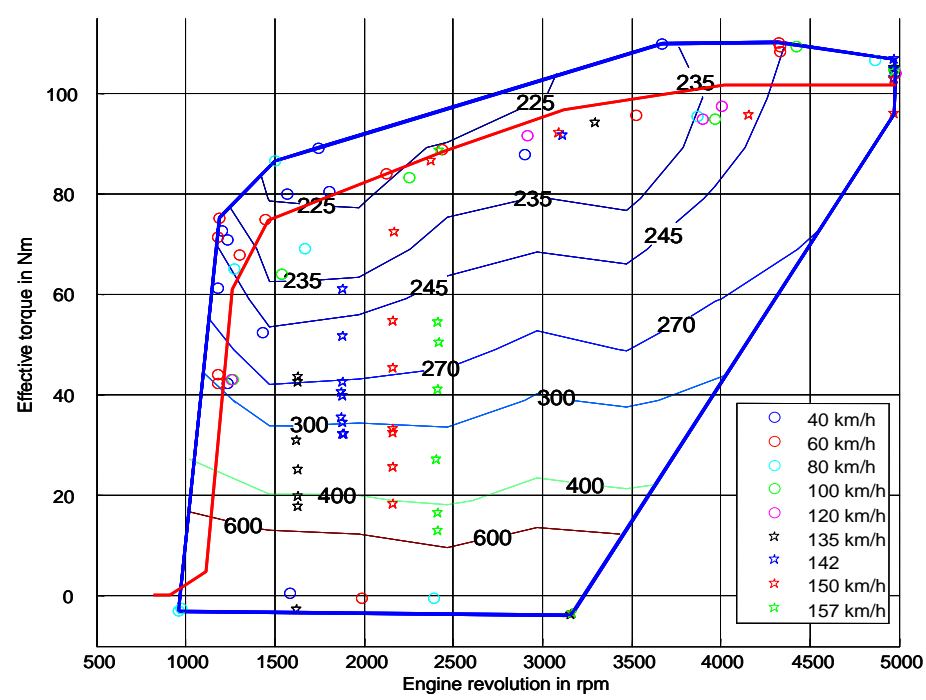

Figure 3 : Specific consumption maps of the ICE in $\mathrm{g} / \mathrm{kWh}$ and measurement points

\subsubsection{ICE restrictive operating range}

As demonstrated below, the limitation on the GEN speed and the mechanical limitation force the ICE to be operated in a restrictive range. Figure 4 illustrates the range of possible operating points of the ICE in the ICE speed/vehicle speed axis. It is clear that at high vehicle speed the ICE has to run at a minimal rpm, even if the required torque is small, and at low vehicle speeds one cannot benefit from the total ICE power due to the limitation on the ICE's maximum possible rpm.

There are at least three limitations which force the ICE to run at a minimum rpm at high vehicle speeds or limit the ICE rpm at low vehicle speeds:

1/ The GEN speed is limited to $10,000 \mathrm{rpm}$, thus if we consider the Willis relation in the planetary gear (figure 4), since the EM speed (equal to the ring speed) is fixed by the vehicle speed, you obtain the following equation:

$$
\frac{\omega_{\max _{-} g e n}-k \omega_{m o t}}{(1-k)}>\omega_{\text {eng }}>\frac{-\omega_{\max _{-} g e n}-k \omega_{m o t}}{(1-k)}
$$

with $\omega_{\text {mot }}:$ EM speed, $\omega_{\text {max_gen }}:$ maximum GEN speed $(10000 \mathrm{rpm}), \omega_{\text {eng }}:$ ICE speed, $\mathrm{k}:$ planetary gear ratio (-2.6).

The relationship between ICE speed and vehicle speed $(\mathrm{V})$ is deduced considering the transmission ratio (4.113) and the wheel radius $(0.3 \mathrm{~m})$ :

$$
\frac{10000}{3.6}+26.26 \mathrm{~V}>\omega_{\text {eng }}>\frac{-10000}{3.6}+26.26 \mathrm{~V}
$$

2/ During our experiments, even at high vehicle speed and whatever the ICE power, the maximum speed recorded on the planet gears is $11,150 \mathrm{rpm}$, even if the GEN speed is well below 10,000 rpm. Considering this as the cause or the consequence of mechanical limitation and inserting this in the planetary gear equation, the following limitation is obtained:

$$
\omega_{\text {mot }}+\omega_{\text {max } \__{-} P} * \frac{P}{A}>\omega_{\text {eng }}>\omega_{\text {mot }}-\omega_{\text {max }_{-} P} * \frac{P}{A}
$$

with $\omega_{\max \_\mathrm{P}}$, maximum planet speed around its axis $(11,150 \mathrm{rpm})$.

with $\mathrm{A}=78$ and $\mathrm{P}=23$ :

$$
36.37 V+3287>\omega_{e n g}>36.37 V-3287
$$

3/ The last limitation is due to the strategy control itself. At a vehicle speed greater than $60 \mathrm{~km} / \mathrm{h}$ the ICE is running at least $1000 \mathrm{rpm}$, whereas the mechanical limitations allow up to $90 \mathrm{~km} / \mathrm{h}$ in electric mode. 

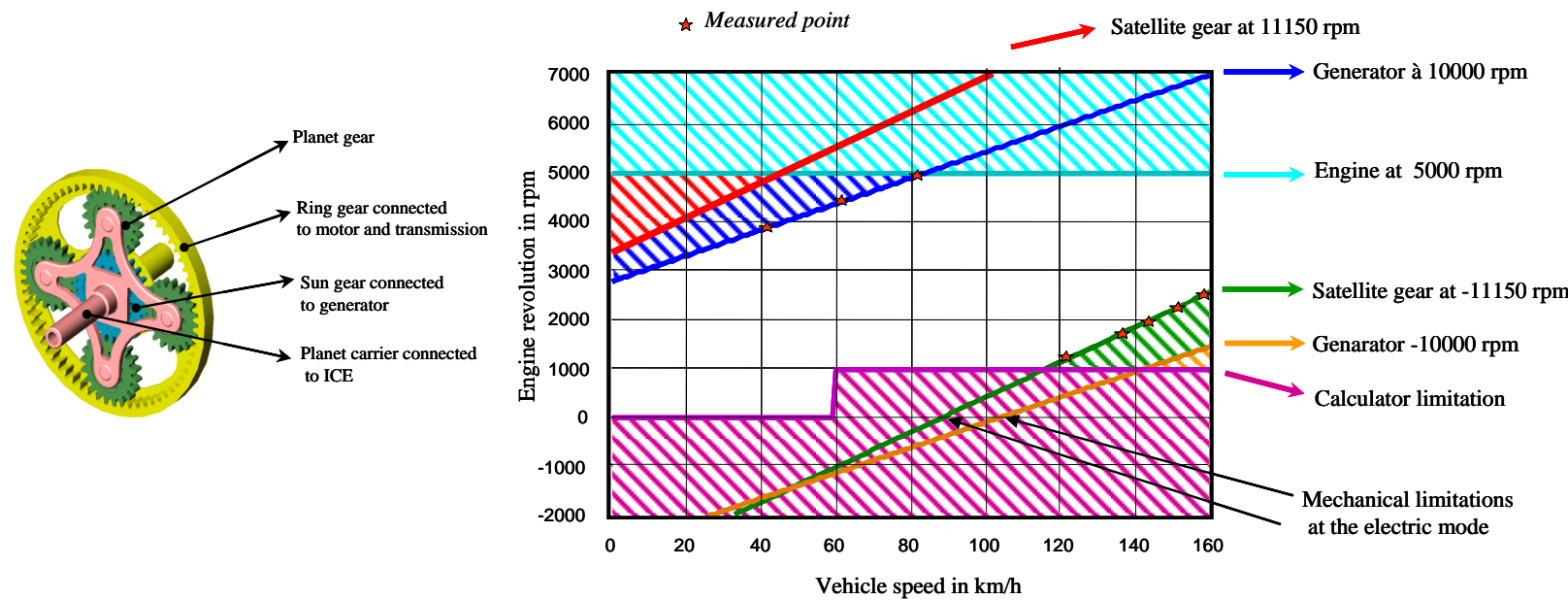

Figure 4: Possible speed operating range of the ICE

\subsection{Battery modelling and testing}

\subsubsection{NiMh battery model}

\subsubsection{Battery voltage evolution}

At rest, a battery is characterised mainly by its output voltage (OCV: Open Circuit Voltage). If the battery contains several elements connected in series, as is the case for the Prius, its voltage is the sum of the individual element voltages.

When a current is applied to a battery, its voltage moves away from its rest value, according to different phenomena:

- State of charge $(\mathrm{SoC})$ variation

- Ohmic drop in the conductors; i.e. the ohmic drop in the electronic conductors itself plus the electrical migration phenomena in the electrolyte that can be approximated by a simple ohmic drop, especially in the case of NiMH batteries.

- Diffusion of ions in the electrolyte and in the porous electrodes, which is a slow process (from minutes to several days).

- In the case of NiMH batteries, a charge-memory effect called "hysteresis". Its effect is a variation of the OCV according to the past currents experienced by the battery: if the battery has been mostly used in charge, the OCV will be greater than if it has been used in discharge, for the same SoC and temperature. This phenomenon was not taken into account in our model. See 'Thele 06' for further information.

- The variation of all the previously listed physical phenomena with temperature. For example, the variation of the diffusion coefficients, or the influence of temperature on the Nernst voltage.

\subsubsection{NiMh battery model used in VEHLIB}

Several levels of simulation are possible:

- a distributed parameter approach that describes the various phenomena occurring in the battery, in the electrical, thermal, and chemical domains,

- a lumped parameter approach in the same physical domains, or only in the electrical domain,

- an empirical approach that does not focus on internal battery operation.

For this study, we used a lumped parameter approach that summarizes all the phenomena in the electrical domain. The chosen equivalent electrical circuit is shown in figure 5. The battery was then simulated thanks to the serial association of:

- two resistors modelling the electrical ohmic drop in the battery, $R d$ for discharge, $R c$ for charge,

- $\quad$ an electromotive force $E$ that models the rest voltage given by the Nernst law,

- a state representation that models the influence of the non-instantaneous diffusion on the Nernst potentials. We call this overvoltage "diffusion voltage", and we write is as $\mathrm{U}_{\mathrm{d}}$. 


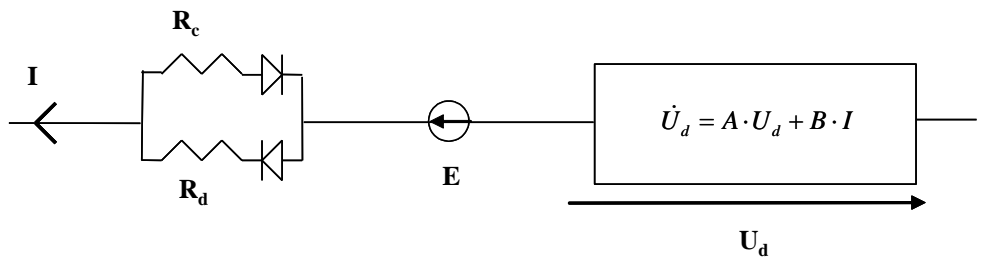

Figure 5 : Electrical equivalent model

Below we describe the approach used to derive the state representation $\dot{U}_{d}=A \cdot U_{d}+B \cdot I$ that models the diffusion phenomenon.

When we consider the diffusion phenomenon from a frequential point of view, it can be shown that its transfer function corresponds to a 0.5 order integrator with a $-10 \mathrm{~dB} / \mathrm{dec}$ ade slope in the Bode gain representation ('Kuhn 04').

It is possible to approximate this slope with a succession of $-20 \mathrm{~dB} / \mathrm{decade}$ and $0 \mathrm{~dB} / \mathrm{decade}$ segments (figure 6). When the frequency approaches zero, it is possible to choose a $0 \mathrm{~dB} /$ decade or $-20 \mathrm{~dB} /$ decade slope. But when we discharge the battery with a current step, we observe that the diffusion voltage rapidly stabilises itself at a given value. So, when the step is long enough, the diffusion phenomena can asymptotically be approximated by a simple resistor that is represented by $0 \mathrm{~dB} /$ decade at low frequency.

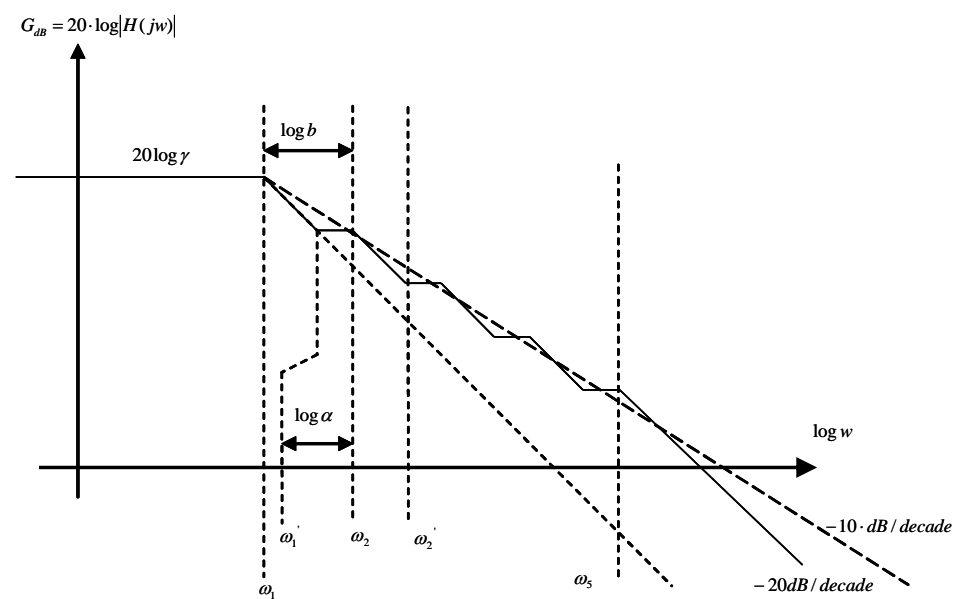

Figure 6 : Approximation of the diffusion phenomena by segments at $0 \mathrm{~dB} /$ decade and $-20 \mathrm{~dB} /$ decade

After several attempts, we considered that an approximation with five $0 \mathrm{~dB} / \mathrm{dec}$ ade segments was sufficient. The parameters to be identified are the frequency $\omega_{1}$ at which the first $-20 \mathrm{~dB} /$ decade segment appears, the frequency ratio $b$ between two identical consecutive segments, and $\alpha$ which defines the segment length at $0 \mathrm{~dB} /$ decade.

$\alpha$ is not set at $0.5^{*} b$ : we then maintain the possibility to approximate a diffusion phenomenon whose slope in Bode gain representation would not be exactly $-10 \mathrm{~dB} / \mathrm{decade}$.

This frequential approximation was translated into the time domain by the state-space representation $\dot{U}_{d}=A \cdot U_{d}+B \cdot I$.

All the model parameters depend on the $\mathrm{SoC}$ and temperature. These parameters were identified with specific tests performed with our DIGATRON battery tester on a $7.2 \mathrm{~V}$ cell. For the time being, these parameters were identified for only one temperature $\left(20^{\circ} \mathrm{C}\right)$.

This diffusion model was integrated into a Simulink S-function.

\subsubsection{Model validation}

The battery S-function model was validated and compared with experimental results. For example, the measured and simulated voltages corresponding to the battery measured current on the vehicle for the NEDC cycle are shown on figure 7 and figure 8 (initial SoC of $60 \%$ ). We compared the recorded voltage with those of our model and together with the one given by a conventional ohmic model E-RI. It clearly appears that when taken into account, the diffusion phenomenon allows a better fit of the model with measurement than a conventional ohmic model does. For example, during the zero current phases - between 290 and 310s or after 
1160 - the voltage remains constant in the ohmic model, whereas measurements and our model show a voltage variation that corresponds to the diffusion phenomenon and appears on the recording.

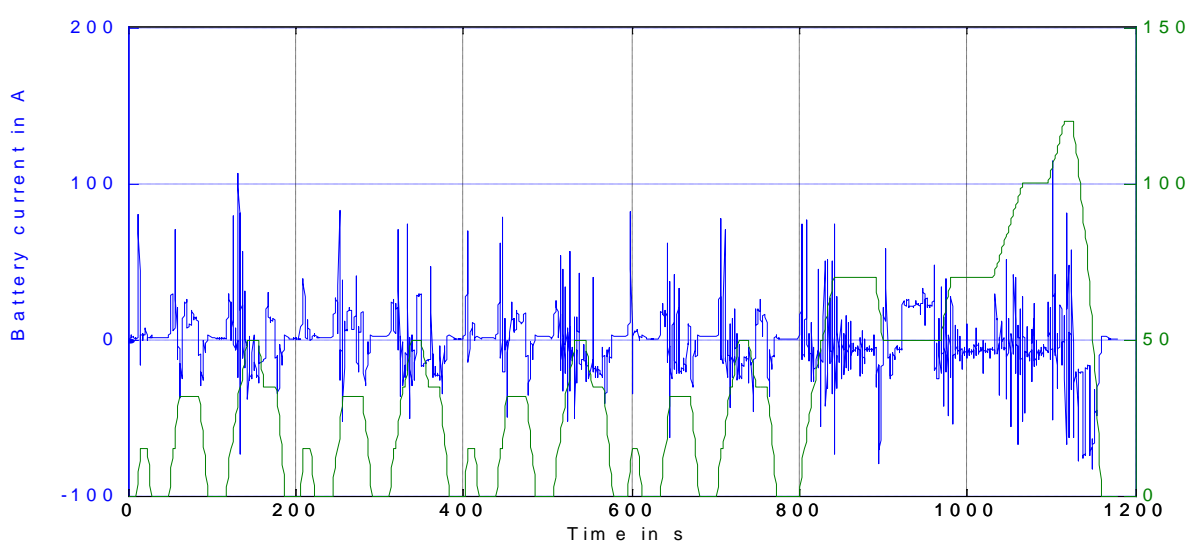

Figure 7 : Battery current for measurement on NEDC cycle.

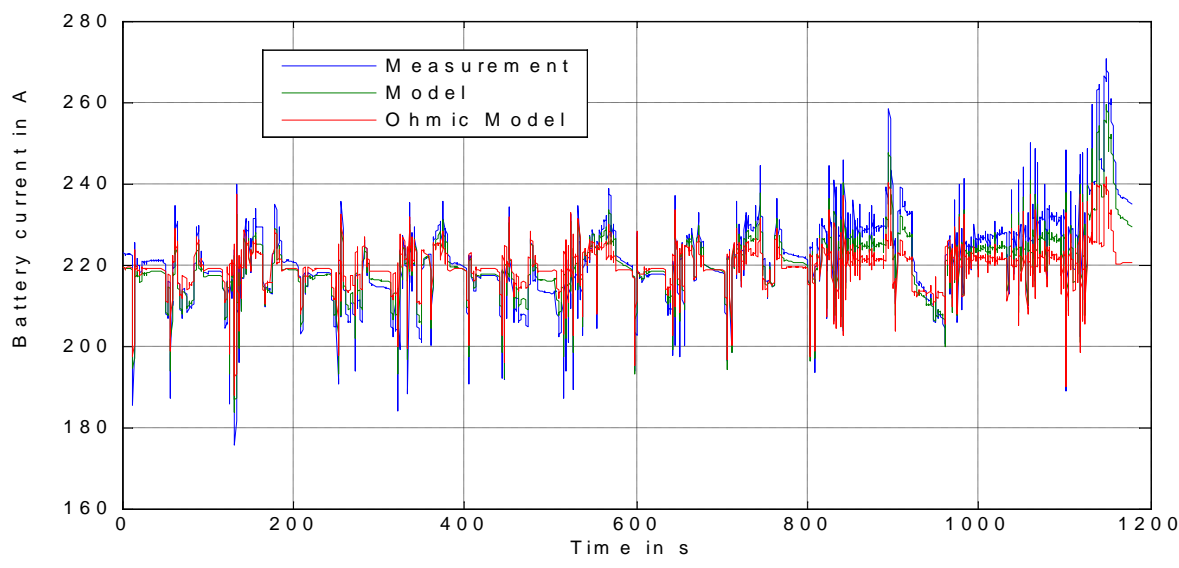

Figure 8 : Battery Voltage for measurement and model on NEDC cycle

\subsection{Boost converter evaluation}

In the THS-II architecture used in the 2004 Prius model, a boost converter is inserted between the battery and the electrical machines' inverters. Thus the EM and GEN voltage may be higher than in the previous version and moreover with fewer battery modules. The possibility of increasing the voltage combined with new electrical machine design allows the machines to provide more power, reduce the flux weakening operations (which decreases electrical machine efficiency), and allows an increase in the maximum GEN speed (6500 to $10,000 \mathrm{rpm}$ ) due to mechanical rotor improvement ('Kamiya 06').

\subsubsection{Boost converter solicitation}

The boost converter model assumes that each of the two electrical machines requires a given voltage supply depending on its torque and speed and gives the maximum voltage required by the two machines ('Okamura 03'). The required voltage was recorded on the chassis dynamometer during the ICE evaluation experiments. The electrical machine torques and speeds and boost converter voltage were also measured. Thus a map of required voltage (figure 9) is deduced for each machine and used in our model, assuming that the boost converter gives the maximum required voltage. 

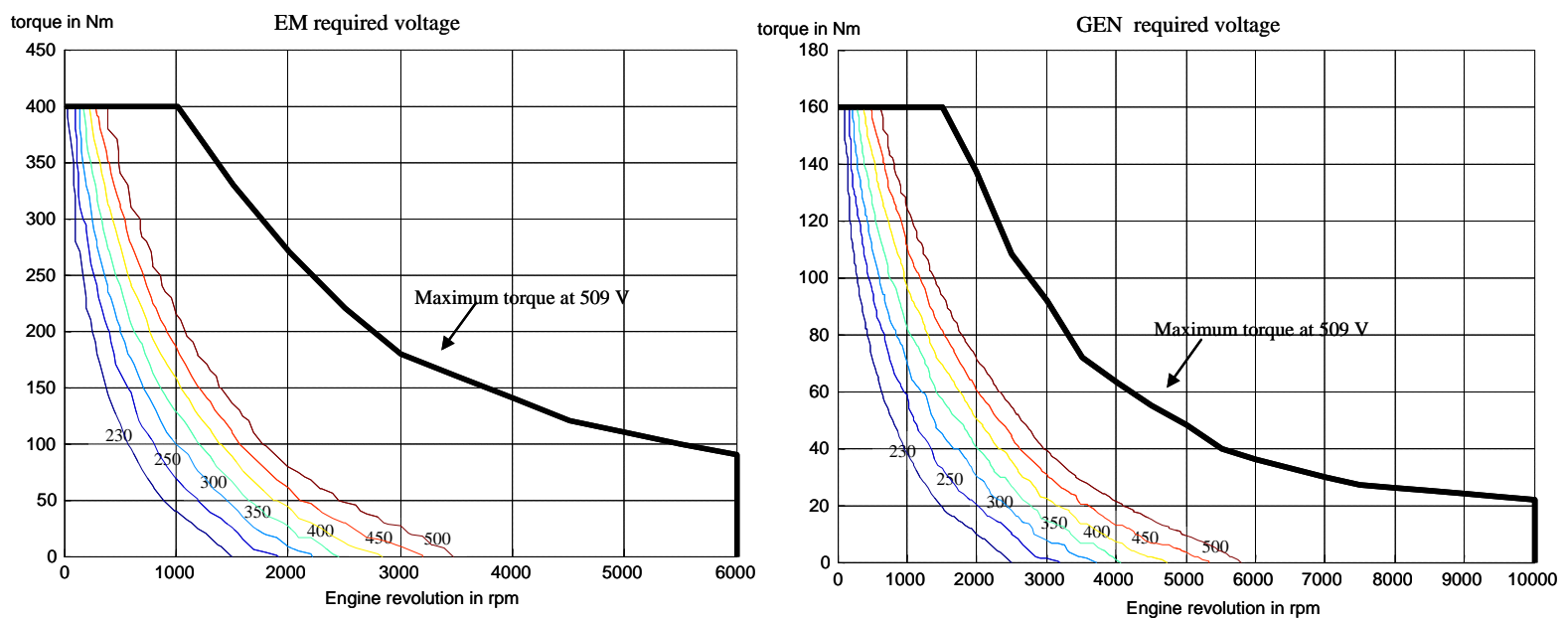

Figure 9 : Required voltage maps for the electrical machines.

\subsubsection{Boost converter model validation}

The boost converter model consists simply of a first order voltage response considering voltage limitation. The losses are analytically calculated considering the component parameters (time fall, reverse recovery charge ...) the battery current, the output voltage, and the chopper frequency.

Figure 10 shows a comparison between simulated and measured boost converter voltage for the extra urban part of the European normalised driving cycle (EUDC).

A good correlation between measurement and simulation is clearly visible. Boost converter minimum voltage is close to $220 \mathrm{~V}$ (corresponding to battery voltage) and the maximum recorded voltage is 510 Volts. One can observe that the difference between simulation and measurement for 900 to 960 seconds is due to strategy differences (hybrid or electrical mode).

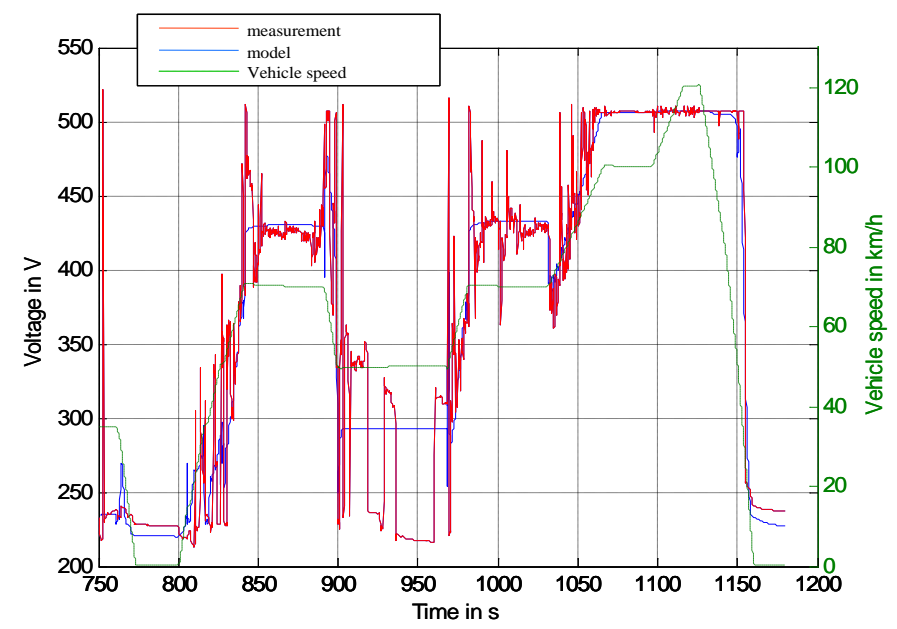

Figure 10 : Boost converter voltage

\subsection{Strategy and THS-II Management deduced from experiments}

Our calculator strategy and THS-II management principle (figure 11) is highly based on the THS drive control principle ('Kimura 99'). The value of the management system parameters (required battery power for example) was determined through measurement (and sometimes by performing specific experiments).

The driver's action on the throttle creates a required torque $\left(\mathrm{T}_{\text {req }}\right)$ on the EM shaft. This torque is transformed into required power $\left(\mathrm{P}_{\mathrm{req}}\right)$ which allows the electric or hybrid mode to be selected (according to vehicle speed $>V_{\text {max_ele }}$ and $\mathrm{SoC}<\mathrm{SoC}_{\min }$ which force the hybrid mode, whatever the other variables). 


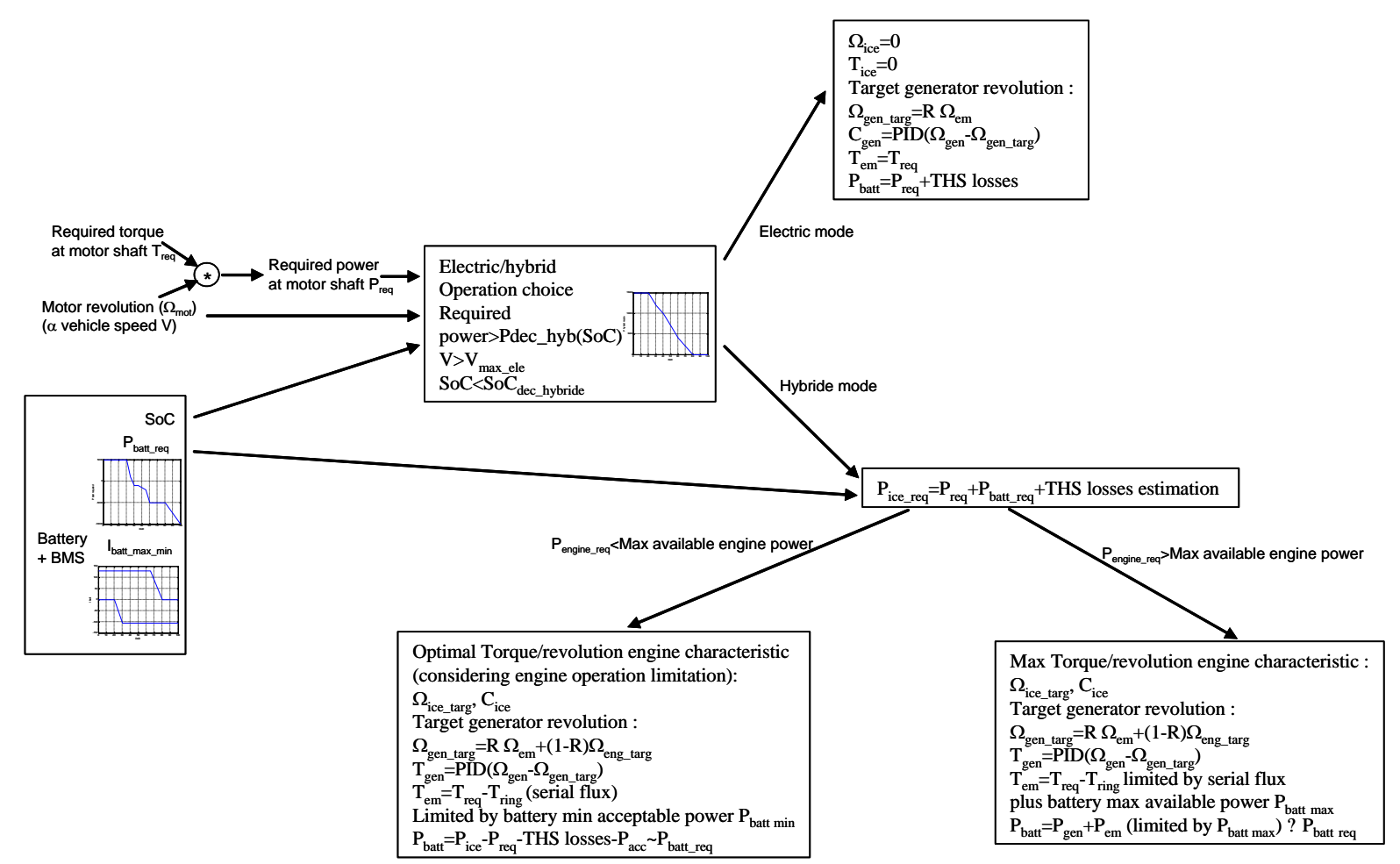

Figure 11 : THS Strategy and Management

\subsubsection{General Cases}

\subsubsection{In electric mode:}

ICE torque and speed are fixed at zero.

Thus the target GEN speed is imposed by the Willis relation on the planetary gear $\Omega_{\mathrm{gen}}=\mathrm{k} \Omega_{\mathrm{em}}$ (with k the planetary gear ratio $=-2.6$ ). The GEN torque is fixed owing to a PID regulation on the GEN speed $\Omega_{\text {gen }}$.

The EM speed is imposed by the vehicle speed (tyre radius $=0.3 \mathrm{~m}$ and gear ratio $=4.113$ ) and its torque is equal to the required torque $\mathrm{T}_{\text {req. }}$.

The battery pack delivers the vehicle required power to which the losses in the components (electrical machine losses and mechanical losses) are added.

\subsubsection{In hybrid mode:}

In hybrid mode, the power required by the ICE is calculated by :

$$
\mathrm{P}_{\text {engine_req }}=\mathrm{P}_{\text {req }}+\mathrm{P}_{\text {batt_req }}+\text { system losses estimation }
$$

where $\mathrm{P}_{\text {batt_req }}$ is the power required by the BMS (Battery Management Systems), depending on the SoC. Then this required power is compared to the maximum available ICE power.

1-If the required power is less than the available power on the ICE:

- The ICE torque and target ICE speed are fixed by an optimal torque/speed characteristic (considering the ICE operation limitation).

- The target GEN speed is calculated by the Willis relation on the planetary gear $\Omega_{\text {generator }}=\mathrm{k} \Omega_{\mathrm{eng}}+(1-\mathrm{k}) \Omega_{\mathrm{mot}}$, and the GEN torque is fixed by a PID regulation on the GEN speed $\Omega_{\text {gen }}$. Note that (at least at standstill) the GEN torque is equal to $-1 /(1-\mathrm{k}) \mathrm{T}_{\text {ice }}$ where $\mathrm{T}_{\text {ice }}$ is positive in the motoring phase, thus the GEN torque is negative, whereas the GEN speed may be positive or negative. This creates two possible directions for the energy flow in EM and GEN (section 3.4).

- The EM torque demand is $\mathrm{T}_{\mathrm{em}}=\mathrm{T}_{\text {req }}-\mathrm{T}_{\text {ring }}$ with $\mathrm{T}_{\text {ring }}=\mathrm{k} /(1-\mathrm{k}) * \mathrm{~T}_{\text {ice }}$. It respects the energy flow (section 3.4) and is limited in the event of regenerative braking in hybrid mode (Vehicle speed > $\mathrm{V}_{\text {max_ele }}$ ) by the minimum accepted battery current (approximately $-100 \mathrm{~A}$ ). In such a phase, the ICE operates at $1000 \mathrm{rpm}$ and almost zero torque.

- The battery power is $\mathrm{P}_{\text {batt }}=\mathrm{P}_{\text {eng }}-\mathrm{P}_{\text {req }}$-system losses $-\mathrm{P}_{\text {acc }}$ and is almost equal to the required battery power $P_{\text {batt_req. }}$ 
2-If the required power is greater than the available power on the ICE alone:

- The ICE torque and target ICE speed are fixed by the maximum available power. In fact, thanks to the THS-II systems, the ICE reaches its maximum power point as quickly as possible.

- The GEN torque and speed are fixed by the same relations as in the previous case.

- The EM torque demand $\left(T_{\text {em }}=T_{\text {req }}-T_{\text {ring }}\right)$ is limited by the sum of the GEN electrical power plus the maximum available battery power (with the maximum current depending on the SoC). This creates the boost phase in which the ICE and battery provide energy to the vehicle.

- The battery power is $\mathrm{P}_{\mathrm{gen}}+\mathrm{P}_{\mathrm{em}}$ corresponding to the boost power; it is highly different from the power required by the BMS.

\subsection{2. "Special" cases}

It is noted that the battery required power depends mainly on the SoC (and other variables such as battery temperature,). It appears that the BMS fixes a target SoC of approximately 58\%. In fact, before 55\% SoC the battery requires a recharge and after $65 \%$ it requires a discharge. Between these two values the battery requires nothing or only a small recharge.

Two special cases included in the system's management may be highlighted:

- If the battery is highly discharged ( $\mathrm{SoC}<\mathrm{SoC} \min =38 \%$ ), the hybrid mode is forced even if the vehicle has stopped, and a minimum current of $20 \mathrm{~A}$ is ensured in the battery, except in the case where a lot of torque is required where the possible battery-provided current is limited above $35 \%$ $\mathrm{SoC}$ and equal to zero above $20 \% \mathrm{SoC}$ (no boost allowed).

- On the other hand, if it is highly charged, above $70 \% \mathrm{SoC}$ the current is progressively limited to reach $20 \mathrm{~A}$ at $80 \% \mathrm{SoC}$ and zero at $83 \% \mathrm{SoC}$ (no regenerating braking is allowed). This was observed by performing a specific test: the chassis dynamometer is used in speed regulation mode at $80 \mathrm{~km} / \mathrm{h}$ and the brake is pushed to approximately $50 \%$. Note that the battery temperature increases from $24^{\circ} \mathrm{C}$ to $26^{\circ} \mathrm{C}$ during this test.
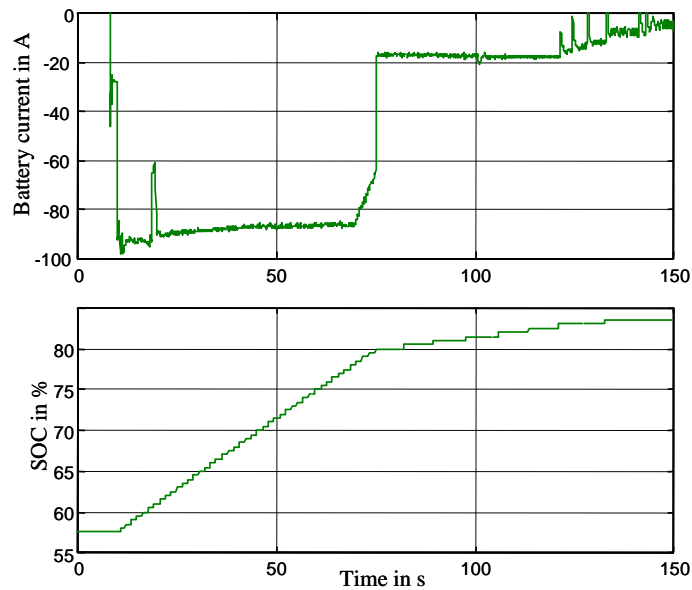

Figure 12 : Maximum regenerative battery capability

Figure 12 shows the battery current and SoC during this test. It clearly appears that after an $80 \%$ SoC the current is first drastically reduced to $20 \mathrm{~A}$ and then to zero when the SoC reaches $83 \%$, which appears to be the maximum authorized $\mathrm{SoC}\left(\right.$ at $\left.25^{\circ} \mathrm{C}\right)$.

Note that the regenerative braking current is limited to $100 \mathrm{~A}$ during braking, and that mechanical braking ensures the rest of the braking.

It is noted that there is another special case, though not yet simulated, which is the cold start of the vehicle, where the ICE is operating during standstill and low speed operation of the vehicle.

\section{VEHICLE SYSTEM VALIDATION}

\subsection{Fuel consumption according to different uses}

The software validation was carried out using a set of different driving schedules, ranging from the specific urban type to the motorway type (figure 13 and table 2) and also dynamic performances.

Table 2 presents a comparison between simulated and measured consumption on the set of driving schedules. The simulation was performed with the variable step method which allows small time steps in highly 
dynamic phases and larger ones the rest of the time. Typical values for the following 10-15 cycles are a mean time step of $0.03 \mathrm{~s}$ with a min value of $0.32 \mathrm{e}^{-18} \mathrm{~s}$ and max value of $0.166 \mathrm{~s}$.

The errors indicated are based on the global cycle consumption and represent the difference between the measurement and simulated values divided by the measurement value. One could note that the errors are of the same order as the measurement precision (less than 5\%), so we can conclude on the acceptable accuracy of the model as far as global vehicle fuel consumption is concerned. Nevertheless it is also important to check the instantaneous variables (3.4.2).
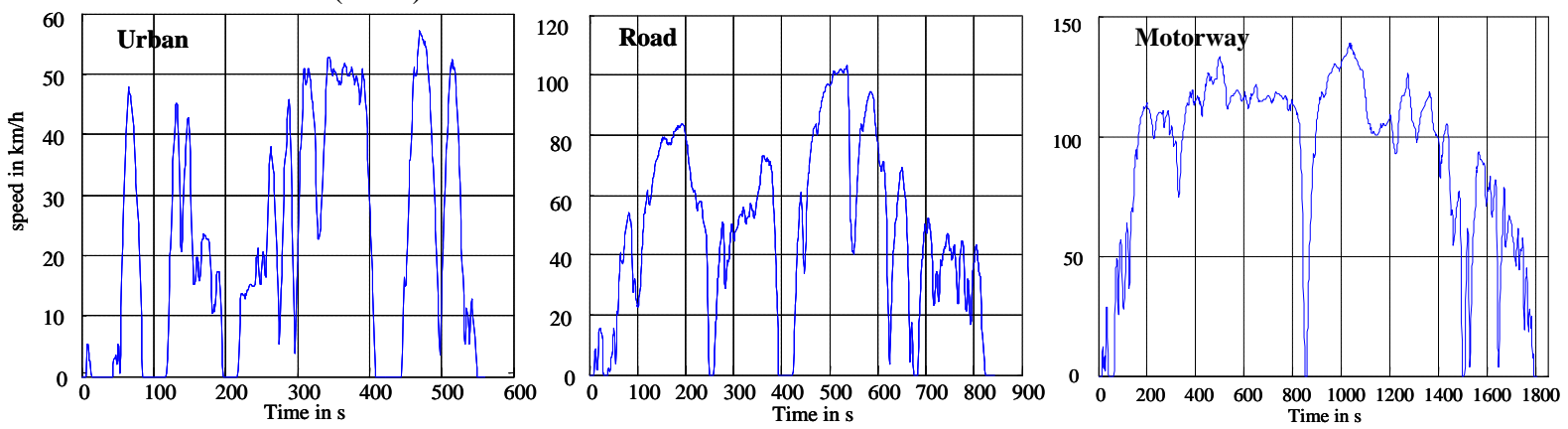

Figure 13 : set of driving schedules

\begin{tabular}{|c|c|c|c|c|c|c|c|c|c|}
\hline Cycle type & $\begin{array}{c}\text { Distance } \\
\text { (in km) }\end{array}$ & $\begin{array}{l}\text { global time } \\
\quad \text { (in s) }\end{array}$ & $\begin{array}{l}\text { Stop time } \\
\text { (in s) }\end{array}$ & $\begin{array}{c}\text { Mean speed } \\
(\mathrm{km} / \mathrm{h})\end{array}$ & $\begin{array}{l}\text { Mean speed } \\
\text { except stop } \\
\text { time }(\mathrm{km} / \mathrm{h})\end{array}$ & $\begin{array}{c}\text { Max speed } \\
(\mathrm{km} / \mathrm{h})\end{array}$ & $\begin{array}{c}\text { Measured } \\
\text { consumption } \\
\text { 1/100 km }\end{array}$ & $\begin{array}{c}\text { Simulated } \\
\text { consumption } \\
1 / 100 \mathrm{~km}\end{array}$ & errors in \%* \\
\hline 1015 modes & 4,2 & 660 & 207 & 22,7 & 33,6 & 69,97 & 3,51 & 3,42 & 2,6 \\
\hline Urban uses & 3,5 & 560 & 132 & 22,3 & 29,6 & 57,2 & 3,88 & 3,73 & 3,9 \\
\hline Road uses & 11,2 & 843 & 82 & 47,9 & 53,5 & 103,4 & 4,23 & 4,28 & $-1,2$ \\
\hline Motorway uses & 46,2 & 1804 & 57 & 92,2 & 95,4 & 138,9 & 5,49 & 5,44 & 0,9 \\
\hline
\end{tabular}

Table 2 : Consumption expressed at zero battery SoC variation for different cycles

\subsection{Instantaneous variables}

\subsubsection{Validation on 10-15 mode cycles}

The instantaneous consumption, the battery SoC and the ICE operation were chosen as relevant validation variables, and presented on a 10-15 mode cycle for three different initial battery SoCs:

- A 55.8\% initial SoC which leads to almost zero SoC variation on the cycle (figure 14)

- A $70 \%$ initial SoC; (80\% SoC corresponds to the maximum authorized capacity) (figure 15)

- A $20 \%$ initial SoC, with the battery deeply discharged (maximum authorized expect critical condition) (figure 16).

It is noted that the other instantaneous variables (electrical machine operation and powers for example) were also validated.

Differences may be noted in the instantaneous consumption, especially on the consumption peak, mainly due to the measurement method with CVS which implies delay and a cutting peak in the exhaust gas measurement, even if it remains accurate in the mean values.

Figures 14 to 16 show that there is a good match between measurement and simulation, which proves that the component models are a good representation of those used in the Prius and also that the strategy is close to that implemented in the vehicle. This appears to be the case, even for the extreme battery SoC where the strategy may be different from "normal" conditions (boost forbidden, negative battery required power ...). It is then noted that for the extremely discharged battery case, the ICE is running (and thus consumes fuel) even if the vehicle is stopped. On the other hand, for high battery SoC the part of the electrical phase is larger than for the cycle with zero SoC variation.

Nevertheless, it is possible to note some differences, especially due to variations in the implemented management laws. For example at instant $180 \mathrm{~s}$ and $330 \mathrm{~s}$ (figure 14), the Prius remains in electric mode in measurement, whereas in simulation it "starts" the hybrid mode during the acceleration. This may be explained by the following two reasons:

- the possible difference in the strategy: power required (depending on SoC) to start the hybrid mode.

- the variation in the vehicle required power, due to following the theoretical driving cycle which cannot be perfect. Nevertheless, especially at zero SoC variation on the cycle, this difference does not matter much since the energy is finally provided by the ICE and thus strategy differences appear to be limited considering the global fuel consumption and the energy flows. 

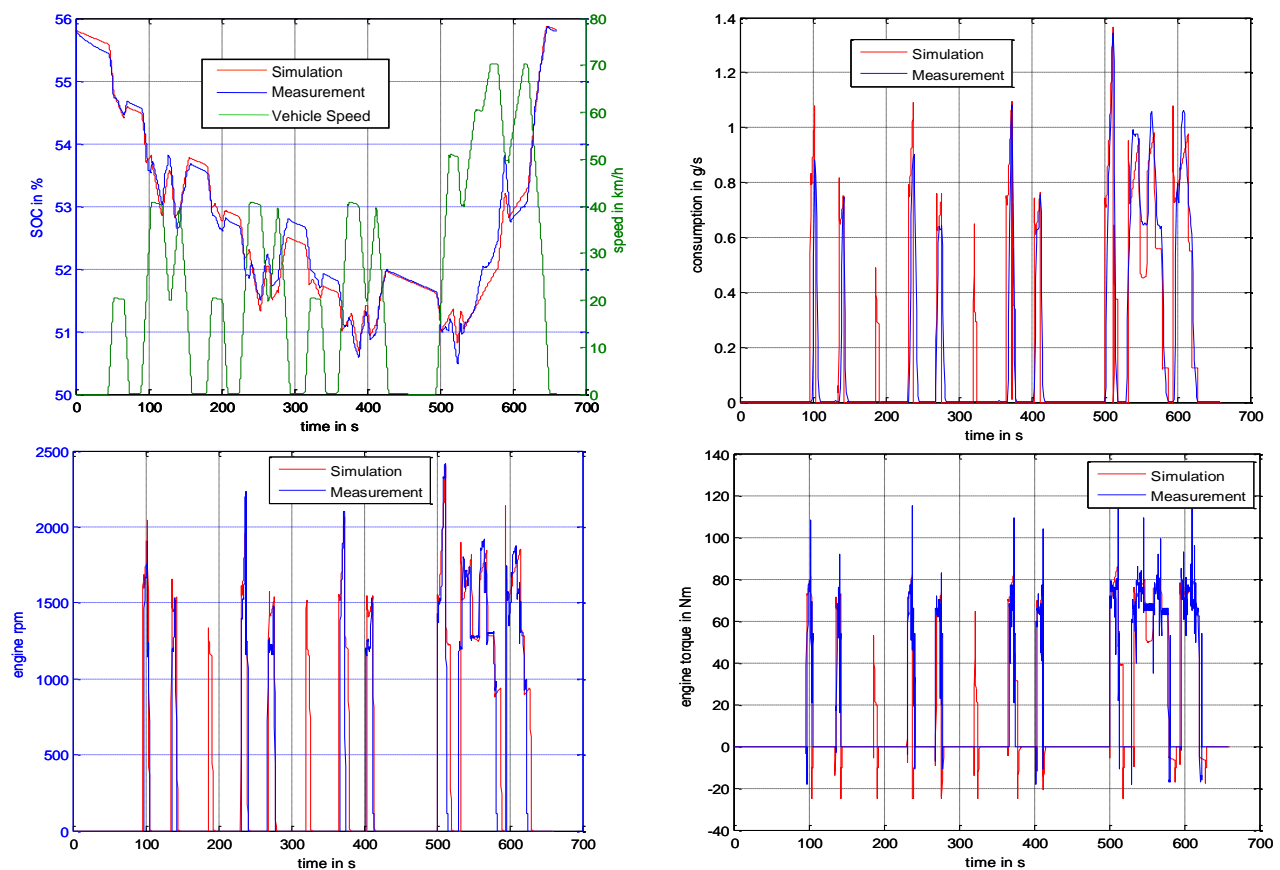

Figure 14 : SoC instantaneous consumption and EM operation on 1015 driving cycle at zero SoC variation.
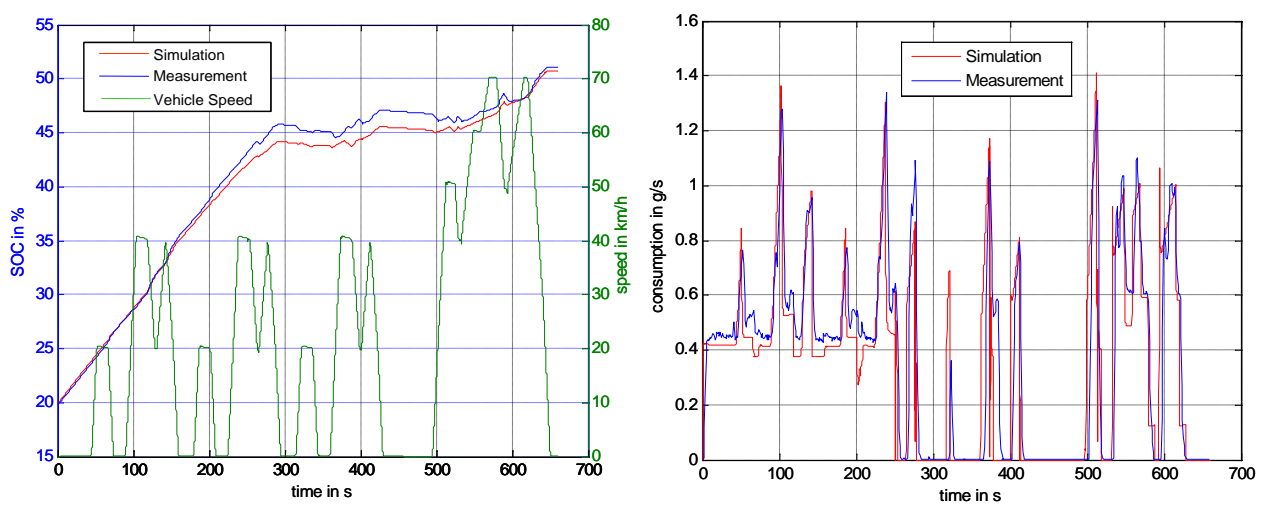

Figure 15 : SoC and instantaneous consumption on 1015 driving cycle for a battery initially discharged (SoC ini $=20 \%$ ).
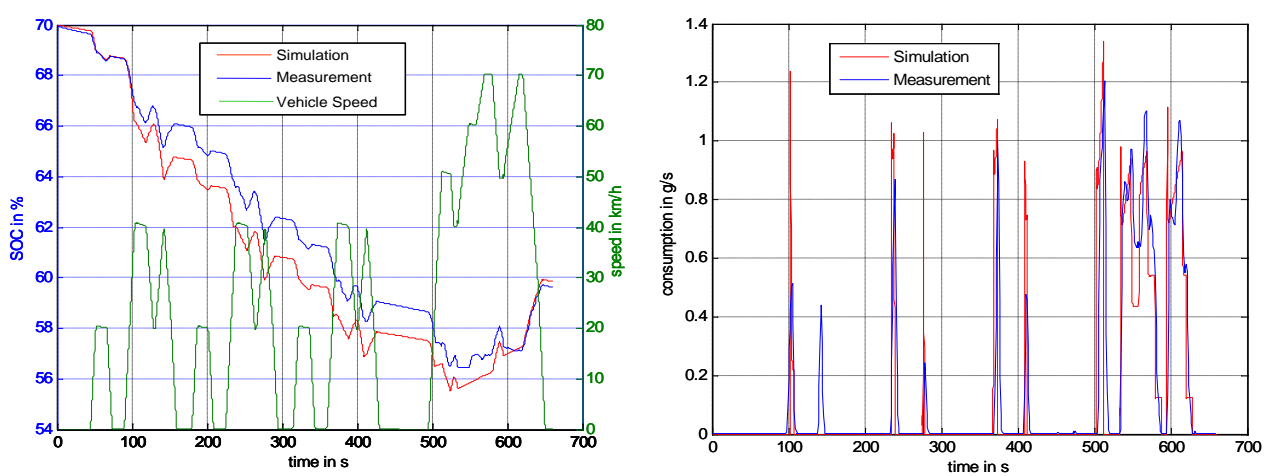

Figure 16 : SoC and instantaneous consumption on 1015 driving cycle for a battery initially charged (SoC ini $=70 \%$ ). 


\subsection{DYNAMIC PERFORMANCE VALIDATION}

The accuracy of the simulation software regarding dynamic vehicle performances is also important, not for the performances themselves but because it reflects the driving comfort (overtaking another car or a truck for example).

Figure 17 shows the 0 to $100 \mathrm{~km} / \mathrm{h}$ acceleration for different battery initial SoCs, and table 3 gives the times from 0 to 50 and 0 to $100 \mathrm{~km} / \mathrm{h}$ accelerations. It is easy to observe the deterioration of performances as the SoC decreases, especially before $30 \%$ where the boost capabilities are highly limited.

Note that at $20 \%$ SoC the battery provides no additional power (boost forbidden) and the vehicle accelerates only with the ICE. Then 0 to $100 \mathrm{~km} / \mathrm{h}$ requires approximately $16.6 \mathrm{~s}$ compared to $11.4 \mathrm{~s}$ when the battery is charged enough to give its maximum available power during acceleration $(20 \mathrm{~kW})$. Data given by Toyota is $11 \mathrm{~s}$ for this acceleration, which assumes that the model is a good representation of the maximum performance available in the Prius 2004

It is important to highlight the fact that in the measurement the time from 0 to 100 and especially from 0 to $50 \mathrm{~km} / \mathrm{h}$ (table 3 ) is longer than in the simulation, for two possible reasons:

- the test was performed on the chassis dynamometer where the wheel-to-roller contact is not as good as on the road and thus it is not possible to accelerate as much as on the road without skidding.

- the contact law is not taken into account in our model.
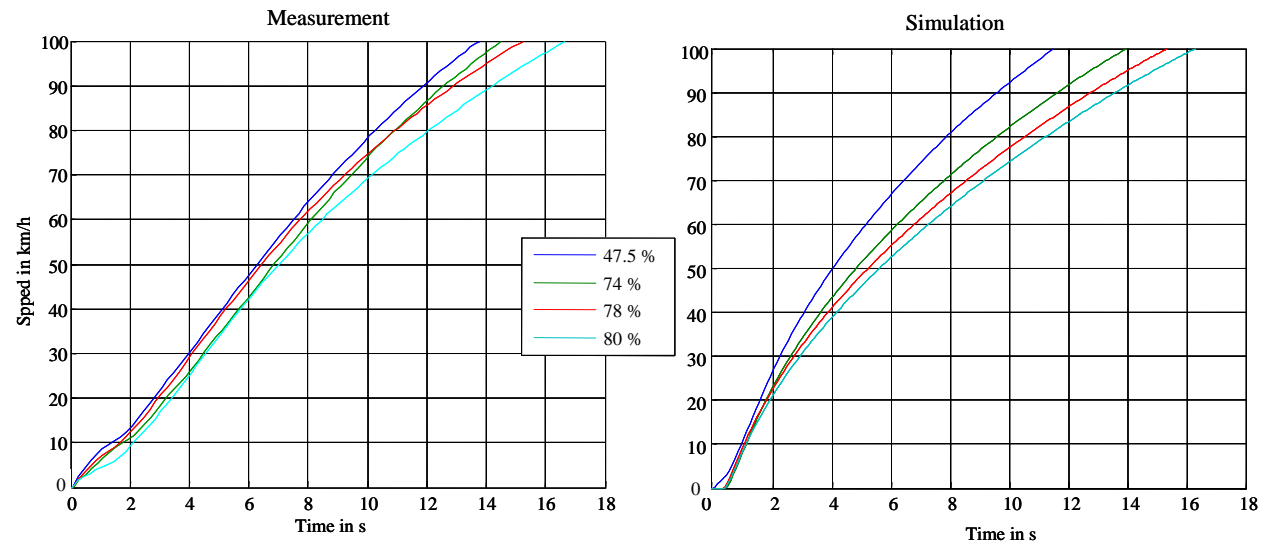

Fig. $17: 0$ to $100 \mathrm{~km} / \mathrm{h}$ acceleration

\begin{tabular}{|c|c|c|c|c|}
\cline { 2 - 5 } \multicolumn{1}{c|}{} & \multicolumn{2}{c|}{ Measurement } & \multicolumn{2}{c|}{ Simulation } \\
\hline SoC ini \% & 0 to $50 \mathrm{~km} / \mathrm{h}(\mathrm{s})$ & 0 to $100 \mathrm{~km} / \mathrm{h}(\mathrm{s})$ & 0 to $50 \mathrm{~km} / \mathrm{h}(\mathrm{s})$ & 0 to $100 \mathrm{~km} / \mathrm{h}(\mathrm{s})$ \\
\hline 52,5 & 6,2 & 13,6 & 4 & 11,4 \\
\hline 26 & 6,5 & 14,5 & 5 & 13,9 \\
\hline 22 & 6,8 & 15,2 & 5,4 & 15,3 \\
\hline 20 & 7 & 16,6 & 5,9 & 16,2 \\
\hline
\end{tabular}

Table $3: 0$ to $50 \mathrm{~km} / \mathrm{h}$ and 0 to $100 \mathrm{~km} / \mathrm{h}$ performances

\subsection{ENERGY FLOW CIRCULATION IN THE THS-II}

\subsubsection{Theoretical approach}

As previously mentioned, in hybrid mode, the energy may flow in the THS-II systems (especially in the EM and GEN) in two directions. The GEN torque is negative most of the time (ICE torque positive), thus depending on the respective EM speed (fixed by the vehicle) and the ICE speed (fixed by the "optimal" strategy), the Willis relation imposes a positive or negative speed on the GEN (figure 18) and thus a positive or negative energy flow in the EM and GEN.

Assuming that the battery provided power is equal to zero, we may have :

- Negative GEN energy (occurs generally at high ICE power/speed), then the flow circulates in an intuitive "normal" direction (figure 18). The energy flow is split in the planetary gear: one part flows directly to the EM shaft, representing a parallel type connection, the other flows through the GEN and the EM, representing a series type connection.

- Positive GEN energy (occurs at low ICE energy/speed), then the electrical energy circulates from EM to GEN. The GEN energy is added to the ICE energy in the planetary gear, and this energy is 
then split in the EM shaft: the part corresponding to the ICE flows to the tyres and the rest flows to the EM.

Note that in both cases the energy that flows through the electrical path creates losses in the components, which is why it may be sometimes important to minimize this electric "path" and explain why an optimal ICE Bsc operating point is not necessarily the optimal power train operating point ('Yaegashi 98').

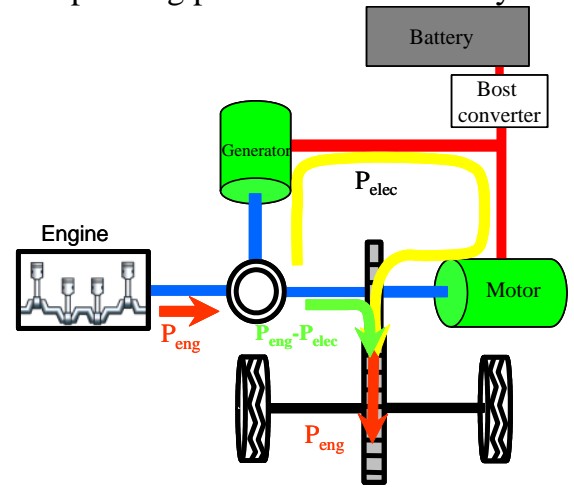

« Normal » energy flow

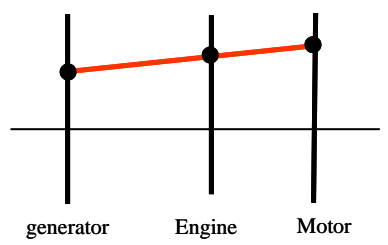

positive generator speed

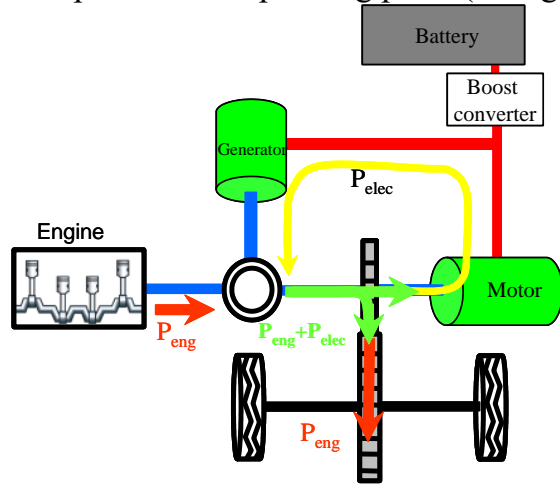

energy re-circulation

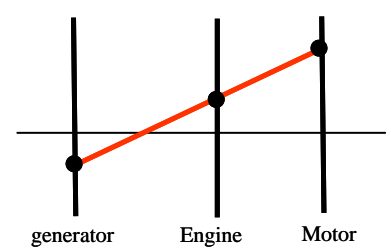

negative generator speed

Figure 18 : energy flow in THS systems

\subsubsection{Validation}

The two different energy paths may be experimentally observed considering the EM, GEN and BAT power, especially if you look at the GEN power. Assuming that the electrical power is positive in the machines when they work as motors (positive mechanical power), and that the battery power never splits in the GEN and in the EM simultaneously, in the hybrid mode, if the GEN power is negative then the system operates in "normal" energy flow, and if it is positive it operates in re-circulation mode.

Figure 19 presents the measured and simulated power on the extra urban part of the NEDC cycle. The alternate phases between the two possible energy flows are clearly noted: normal energy flow for high required power (vehicle acceleration) and re-circulation for low required power (constant speed). Measurement and simulation are close enough to confirm the relevance of our model, especially concerning the THS-II strategy representation and behaviour. Note the phase of electrical mode and the low electrical power necessary to equilibrate the planetary gear.

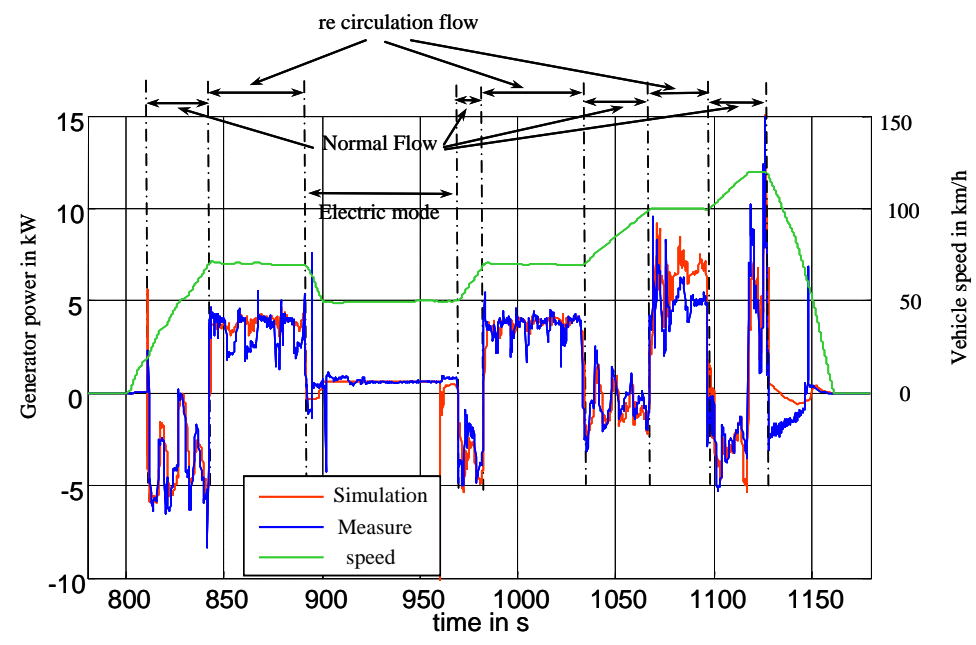

Figure 19: GEN power on EUDC uses cycle 


\section{EXAMPLE OF AN APPLICATION: COMPARISON WITH A CONVENTIONAL VEHICLE}

\subsection{Hypothesis}

After being developed and validated, this model was used for certain studies of more general hybrid architectures, but also to better understand phenomena which are difficult to observe with instrumentation in the Prius itself.

An example of an application is given in this section, comparing the energy flow and the ICE operation in a conventional vehicle and in the THS-II.

The conventional car is an equivalent conventional vehicle, with the same chassis, equivalent dynamic performances and global transmission maximal power, and a bit lighter to take into account the weight of the hybrid transmission (see table 4).

The software enables us to completely forecast the energy flow in the power train components. Results for an urban cycle are presented and compared for the conventional car and the Toyota Prius (section 4.1), then the ICE operation points are presented and discussed for different types of use (section 4.2).

\begin{tabular}{|c|c|c|}
\cline { 2 - 3 } \multicolumn{1}{c|}{} & Conventional vehicle & Prius \\
\hline Vehicle weight & $1308 \mathrm{~kg}$ & $1360 \mathrm{~kg}$ \\
\hline Engine characteristics & $83 \mathrm{~kW} @ 5400 \mathrm{rpm}$ & $56 \mathrm{~kW} @ 5000 \mathrm{rpm}$ \\
& $151 \mathrm{Nm} @ 4250 \mathrm{rpm}$ & $110 \mathrm{Nm} @ 4250 \mathrm{rpm}$ \\
\hline $0->100 \mathrm{~km} / \mathrm{h}$ & $12,3 \mathrm{~s}$ & $11,7 \mathrm{~s}$ \\
\hline Maximum Power & $83 \mathrm{~kW}$ & $81 \mathrm{~kW}$ \\
\hline
\end{tabular}

Table 4 : Vehicle characteristics

\subsection{Energy flow in a conventional car and in the Prius 2004}

\subsubsection{Objective power train comparison}

The idea is to compare the power trains (the system between ICE and wheel plus shaft), independently from the ICE characteristics (Bsc) and the gear ratio choice (which may highly influence consumption), and thus to make a comparison of respective losses in the two architectures.

The software enables precise evaluation of the energy flows exchanged by the components' power train. One could note that:

- Due to too much possible operation in THS-II systems (motoring or braking phase, electrical or hybrid mode, normal or re circulation phases) it seems relevant to indicate the energy as the average energy which flows in or out of each component during the entire cycle, whatever the power train operation.

- For each component, the energy flow balance (energy entering minus energy going out) is equal to the component's internal losses.

As far as the vehicle is concerned, the energy flow is shared among dissipative loads (aero, rolling), inertia (partially recovered during braking phases) and braking losses (no altitude variations are considered in our case).

It is assumed that every car possesses some obvious accessories (ventilation, dashboard ...), and hybrid systems often possess additional accessories (such as a cooling circuit for power electronics and electrical machines, battery ventilation ...), which should be included in the power train. Therefore there are "external" $150 \mathrm{~W}$ accessories in each architecture and additional "internal" $100 \mathrm{~W}$ accessories in the Prius. It is assumed that those powers remain constant during the cycle and represent the mean of the power observed in our measurement.

Note that in the conventional car (with no stop/start capability) the battery is almost only used to start the ICE and will have no influence on the global flow.

\subsubsection{Comparison between a conventional car and the Prius 2004}

Figure 20 and figure 21 present the general energy flow (expressed in $\mathrm{Wh} / \mathrm{km}$ ) in a conventional vehicle and in the Prius 2004. With simulation it is possible to have easy access to all relevant variables (even to 
some that may be difficult to measure, such as electrical machine torques for example).

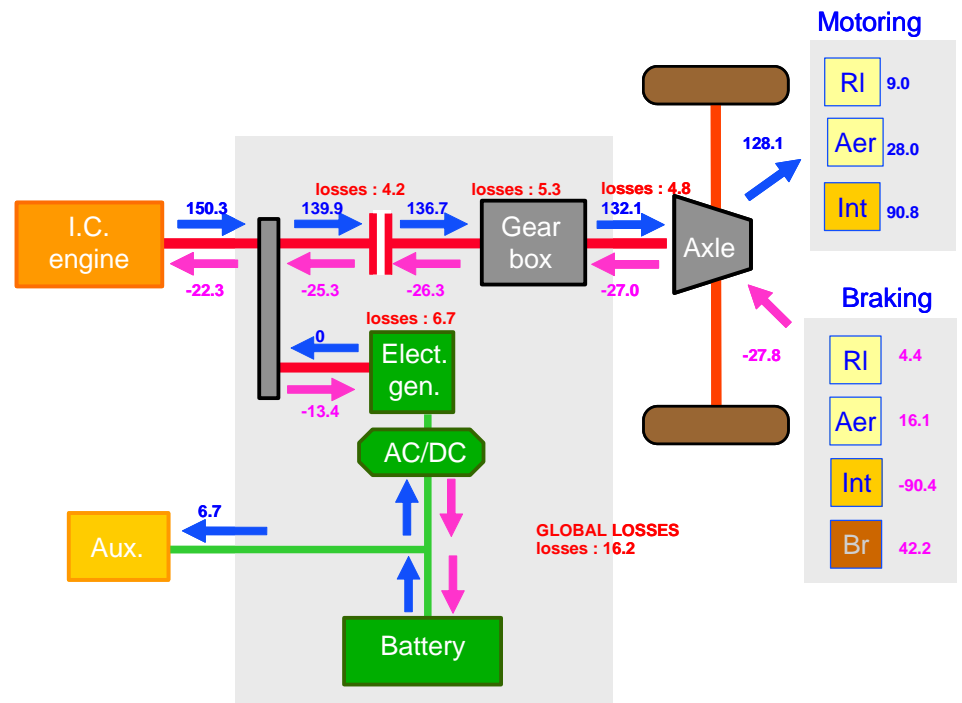

Figure 20 : Energy flow in $\mathrm{Wh} / \mathrm{km}$ in conventional vehicle in urban uses

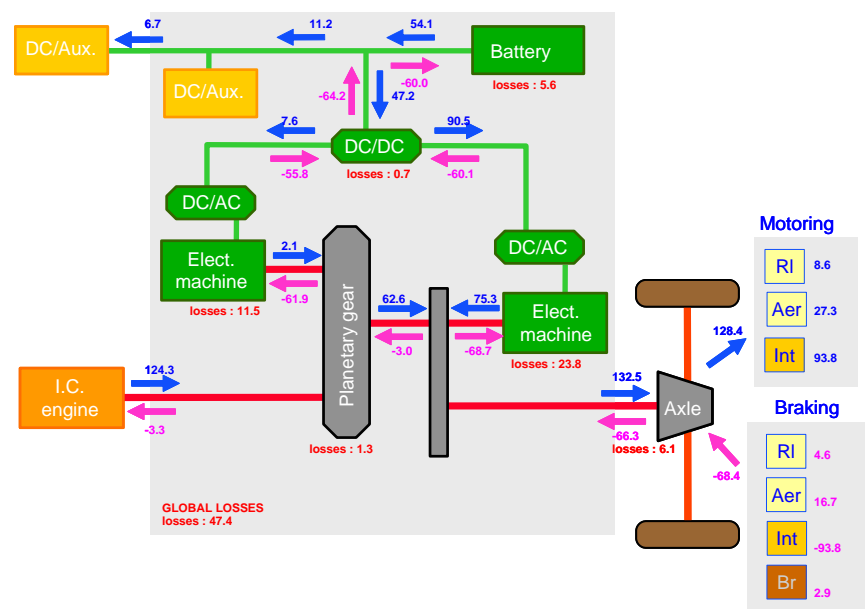

Figure 21 : Energy flow in $\mathrm{Wh} / \mathrm{km}$ in Prius vehicle in urban uses

For the same cycle the energy sent to the shaft in the motoring phase is slightly higher for the Prius due to the power train's extra weight.

The global losses appearing in figure 20 and figure 21 represent the sum of the losses inside the transmission, i.e. mechanical losses, electrical machine losses, additional accessory consumption, and losses from the battery, which at zero SoC variation is only an energy storage device with a certain efficiency. It excludes the shaft losses inherent to each vehicle. The Motoring and Braking energy are separated into rolling $(\mathrm{Rl})$, aero (Aer), inertia (Int) and braking (Br) energy.

Finally, it is important to note that the ICE supplied energy in the Prius is $124.3 \mathrm{Wh} / \mathrm{km}$ compared to 150.3 Wh/km, which represents only an $18 \%$ reduction compared to at least a $40 \%$ reduction in fuel consumption currently announced for urban use. This reduction in ICE supplied energy is mainly due to the regenerative braking capability. The braking energy flowing into the transmission is the highest in the Prius systems (68.4 Wh/km compared to $27.8 \mathrm{Wh} / \mathrm{km}$ in a conventional power train due to mechanical braking) and moreover is principally used to recharge the battery (reduced by losses), whereas it represents ICE braking in a conventional car. Note that the potentially reusable energy is the kinetic energy provided during the motoring phase minus the aerodynamic and rolling losses during the braking phase (minus a small mechanical braking energy in urban uses), thus not all the kinetic energy may be "re-used".

The rest of the gain is then mainly due to the ICE operation point during the cycle (see section 4.2). Thus it is interesting to compare the energy dissipation in the vehicle. figure 22 presents the distribution of the dissipated energy expressed as a portion of the energy produced by the ICE. 
Global losses in conventional power trains represent less than $11 \%$ of the energy supplied by the ICE $(150.3 \mathrm{Wh} / \mathrm{km})$. On the other hand, the global losses are higher in the Prius transmission (38\%). They represent a non negligible portion of the energy supplied by the ICE $(124.3 \mathrm{Wh} / \mathrm{km})$ and are high compared to the motoring energy required for the vehicle's progression (47\%). This is the price to pay for particularly efficient systems and ICE operations (see section 4.2).

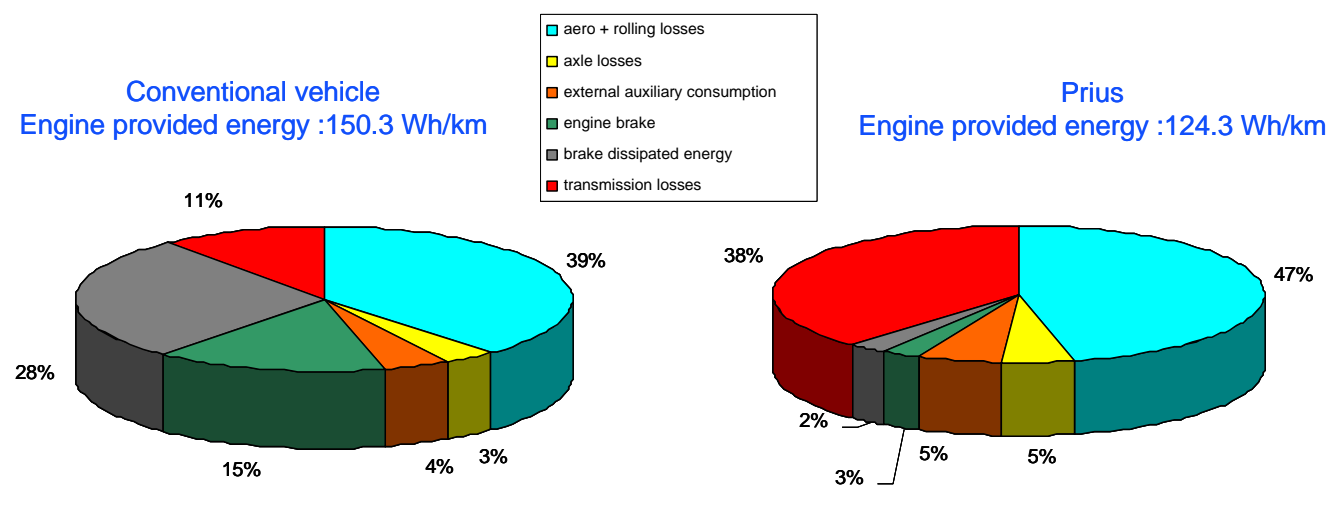

Figure 22 : energy dissipation in urban uses

\subsection{ICE operating during different vehicle uses}

This section presents the ICE operation point for the two considered power trains (figure 23 to figure 25). The Bsc map of the conventional vehicle is given as an example representing a current gasoline ICE characteristic. One could also note that the gear ratio is chosen as representative of normal driving and is not at all optimized to minimize consumption. Thus no consumption may really be announced, however the ICE power or energy is a more relevant variable as it is not influenced by Bsc maps and hardly influenced by the gear box ratio. vehicles.

This part presents the ICE working range for urban, road and motorway cycles, for the two considered

The figures represent, in torque speed axis, the ICE operation points, calculated with our model (500 points per cycle equally time-spaced).

This representation clearly highlights that:

The ICE operation is highly influenced by the vehicle's type of use for the conventional power train, and globally reaches higher torque as the driving schedule requires more power (urban to motorway), nevertheless generally remaining in relatively poor Bsc ranges.

In the Prius, thanks to the sophisticated power train and smart management, the ICE working range is close to the 'optimal' curve fixed by the strategy management. In fact, these cycles did not require much power and thus the ICE seldom moved away from this characteristic (as it may occur with high dynamic required torque).

It is noted that the gain is also due to the downsizing of the ICE and the possibility of the use of a High-Expansion Ratio Cycle (Atkinson cycle 'Toyota 03') engine in the Prius with better Bsc for a similar operation point.
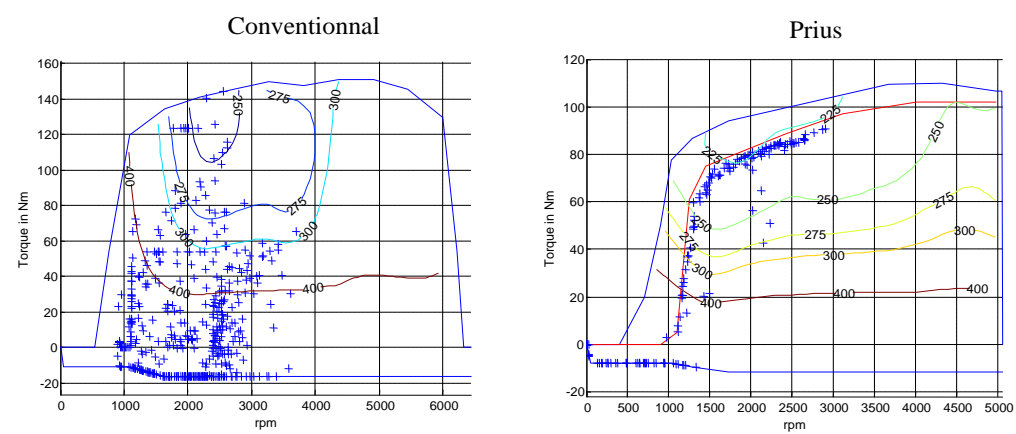

Figure 23 : ICE operation in urban uses 

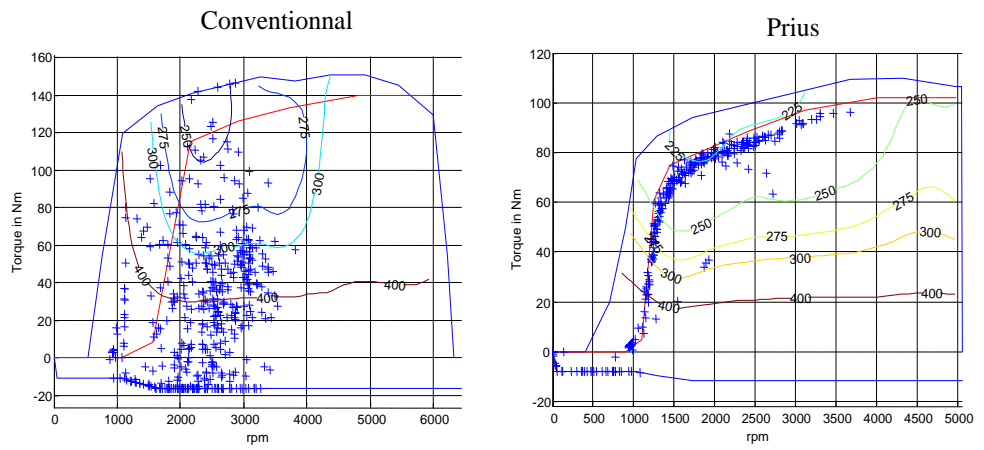

Figure 24 : ICE operation in road uses
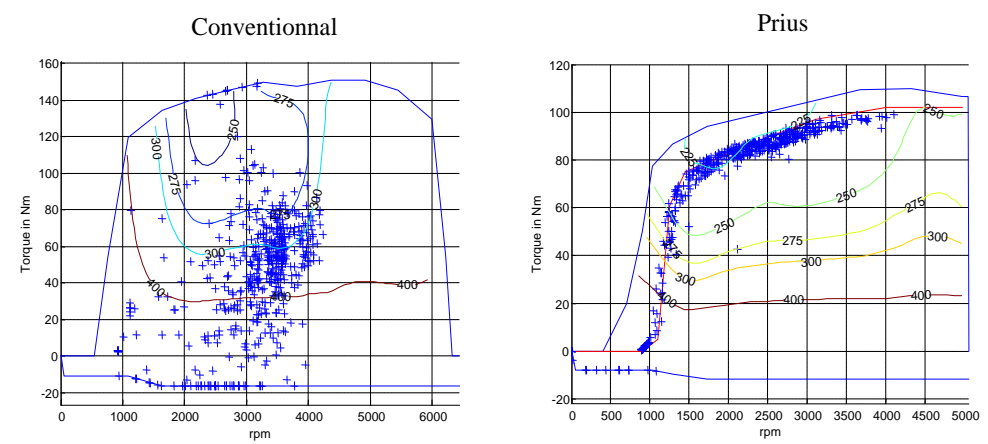

Figure 25 : ICE operation in motorway uses

\section{Conclusion}

A complete measurement and evaluation campaign was carried out with an instrumented vehicle on a chassis dyno and battery element on a battery test. Thanks to these measurements, a simulating model of the 2004 Prius, its components and management law was developed and inserted into VEHLIB, the INRETS vehicle simulation library. It indicates a very good correlation between measurement and simulation for significant variables (consumption, battery charge, energy flow ...).

This model has already been used to highlight the detailed energy flow and potential gain for different types of conventional and hybrid power trains. Other studies on split power architecture in general are currently being performed. This validated software program will now be used to evaluate fuel consumption benefits for different hybrid power train architecture types and components according to vehicle use.

\section{Acknowledgement}

The authors wish to thanks the French Environment and Energy Management Agency (ADEME) for their financial support together with the partners of the EVALVH evaluation program.

\section{References}

[Combes 98] E. Combes, M. Delhom, J. Personnal. Parallel Hybrid Traction System and Mechatronic Design. FISITA Congress proceeding. Paris, September 1998.

[Jeanneret 99] B. Jeanneret, R. Trigui, F. Badin, F. Harel, New Hybrid concept simulation tools, evaluation on the Toyota Prius car, $16^{\text {th }}$ international electric vehicle symposium, Beijing, China, October 13-16, 1999.

[Jeanneret 04] B. Jeanneret, R. Trigui, B. Malaquin, M. Desbois-Renaudin, F. Badin, C. Plasse, Jscordia. "Mise en oeuvre d'une commande temps réel de transmission hybride sur banc d'essai moteur ». 2nd European conference : Alternatives énergétiques dans l'automobile. April 2004, Poitiers France.

[Kamiya 06] M. Kamiya, Development of traction Drive Motors for the Toyota Hybrid System, IEEJ Trans. IA, Vol. 126, $\mathrm{N}^{\circ} 4$, pp 473-479 (2006).

[Karnopp 90] D. Karnopp, D. L. Margolis, R.C.Systems dynamics: a unified approach, Second edition. Wiley_Interscience, New York, USA, 1990. 
[Kimura 99] A. Kimura, T. Abe, S. Sasaki, Drive force control of a parallel-series hybrid system, JSAE Review, 1999, pp 337-341.

[Kuhn 04] E. Kuhn, Contribution à la conception optimale d'une motorisation hybride parallèle : choix d'un modèle d'accumulateur. Université de Technologie de Compiègne. 2004.

[Liu 05] J. Liu, H.Peng, Z.Filipi, Modelling and Analysis of the Toyota Hybrid System. IEEE Proceedings on International Conference on Advanced Intelligent Mechatronics 2005, pp. 134-139.

[Lukic 03] S. M. Lukic and A. Emadi, Modelling electric motors using efficiency maps, Electrical Insulation Conference and Electrical Manufacturing and Coil Winding Technology Conference, 23-25 September, 2003, pp 543-550.

[Markel 02] T. Markel, A. Brooker, T. Hendricks, V. Johnson, K. Kelly, B. Kramer, M. O’Keefe, S. Sprik, K. Wipke. Advisor. A systems Analysis Tool for Advanced Vehicle Modelling. Journal of power sources (2002), Vol. 110, Number 2, August 2002, pp. 255-266.

[Muta 04] K. Muta, M. Yamazaki, J. Tokiada, Development of New Generation Hybrid System THS II - Drastic Improvement of Power Performance and Fuel Economy, SAE Technical Paper 2004-01-0064.

[Okamura 03] M. Okamura, E. Sato, S. Sasaki, Development of Hybrid Electric Drive System Using a Boost Converter, EVS, November, 2003.

[Rousseau 00] A. Rousseau, and R. Larsen,., Simulation and Validation of Hybrid Electric Vehicles Using PSAT Global Powertrain Congress, Detroit (June 2000).

[Rousseau 01] A. Rousseau, and M. Pasquier., Validation Process of a System Analysis Model: PSAT, SAE paper 01P-183, SAE World Congress, Detroit (March 2001).

[Rousseau 04] A. Rousseau, J. Kwon, P. Sharer, S. Pagerit, M. Duboa, Integrating Data, Performing Quality Assurance, and Validating the Vehicle Model for the 2004 Prius Using Psat, SAE paper 2006-01-0667, SAE World Congress, Detroit (April 2006).

[Scordia 05] J.Scordia ,M.Desbois-Renaudin, R.Trigui, B.Jeanneret and F.Badin. Global Optimization of Energy Management Laws in Hybrid Vehicles Using Dynamic Programming. I.J.Vehicle Design,Vol.39,No.4,2005.

[Takaoka 04] T. Takaoka, G.Killmann, Toyota Hybrid Systems, Congrès alternatives énergétiques dans l'automobile, Futuroscope, 7-8 April 2004, pp1-11.

[Thele 06] M. Thele, M. Radin-Macukat, D. Sauer, O. Bohlen, D. Linzen, Impedance-based modelling of electrochemical energy storage devices - a successful implementation for NiMH batteries used in design tools for hybrid electric vehicles. Electric Vehicle Symposium 22. 10/2006.

[Toyota 03] Toyota Hybrid System THS II, SpecialReports_12 Toyota Motor Corporation, Publics affairs Division, available at www.toyota.co.jp/en/tech/environment/ths2/SpecialReports_12.pdf

[Trigui 03] R. Trigui et al, Hybrid light duty vehicle evaluation program, International Journal of automotive technology, Vol. 4, $\mathrm{N}^{\circ}$ 2, pp. 65-75 (2003).

[Trigui 04-a] R. Trigui, B. Jeanneret, F. Badin, Systemic modelling of hybrid vehicles in order to predict dynamic performance and energy consumption Building the VEHLIB library of models, RTS (Revue Transport et Sécurité) 83, pages 129-150, 2004, ISSN Nº: 0761-8980, Lavoisier edition.

[Trigui 04-b] R. Trigui, M. Desbois-Renaudin, B. Jeanneret, F. Badin, J.Scordia, C. Plasse, Global ForwardBackward Approach for a Systematic Analysis and Implementation of Hybrid Vehicle Management Laws. Application to a Two Clutches Parallel Hybrid Power Train, EET 2004, March 18-20th, 2004, Estoril, Portugal.

[Trigui 07] R. Trigui, B. Jeanneret, B. Malaquin, F. Badin, C. Plasse, Hardware In the Loop Simulation of a Diesel Parallel Mild-Hybrid Electric Vehicle. IEEE VPPC 07. 9-12 September 2007. Arlington, Texas.

[Vinot 07] E. Vinot, R. Trigui, J. Scordia, B. Jeanneret, F. Badin HEVs comparison and components sizing using dynamic programming, IEEE, VPPC 07, 9-12 September 2007, Arlington, Texas.

[Wang 02] W. Wang, Revisions on the Model of Toyota Prius in Advisor 3.1. SAE Technical Paper. Document Number: 2002-01-0993

[Wipke 99] K. B. Wipke, M. R. Cuddy, and S. D. Burch, ADVISOR 2.1: A User-Friendly Advanced Powertrain Simulation Using a Combined Backward/Forward Approach, IEEE Transactions on Volume Vehicular Technology, 48, Issue 6, Nov 1999 Page(s): 1751 - 1761 
Original paper published in: Int. J. Vehicle Systems Modelling and Testing, Vol. 3, No. 3, 2008

https://doi.org/10.1504/IJVSMT.2008.023835

[Yaegashi 98] T. Yaegashi, S. Sasaki, T. Ave, Toyota Hybrid System: its concept and technologies, FISITA 98, September 1998, Paris, France. 